\title{
Evaluating Covariance Matrix Forecasts in a Value-at-Risk Framework
}

\author{
Jose A. Lopez \\ Economic Research Department \\ Federal Reserve Bank of San Francisco \\ 101 Market Street \\ San Francisco, CA 94705 \\ Phone: (415) 977-3894 \\ Fax: (415) 974-2168 \\ jose.a.lopez@sf.frb.org
}

\author{
Christian A. Walter \\ Group Risk Management \\ Credit Suisse Group \\ Nueschelerstrasse 1 \\ 8070 Zurich, Switzerland \\ Phone: +41 13337476 \\ Fax: +41 13337516 \\ christian.a.walter@csg.ch
}

Draft date: April 17, 2000

\begin{abstract}
:
Covariance matrix forecasts of financial asset returns are an important component of current practice in financial risk management. A wide variety of models, ranging from matrices of simple summary measures to covariance matrices implied from option prices, are available for generating such forecasts. In this paper, we evaluate the relative accuracy of different covariance matrix forecasts using standard statistical loss functions and a value-at-risk (VaR) framework. This framework consists of hypothesis tests examining various properties of VaR models based on these forecasts as well as an evaluation using a regulatory loss function.

Using a foreign exchange portfolio, we find that implied covariance matrix forecasts appear to perform best under standard statistical loss functions. However, within the economic context of a VaR framework, the performance of VaR models depends more on their distributional assumptions than on their covariance matrix specification. Of the forecasts examined, simple specifications, such as exponentially-weighted moving averages of past observations, perform best with regard to the magnitude of VaR exceptions and regulatory capital requirements. These results provide empirical support for the commonly-used VaR models based on simple covariance matrix forecasts and distributional assumptions.
\end{abstract}

Acknowledgments: The opinions expressed in this paper are those of the authors and do not necessarily reflect the views of the Credit Suisse Group, Federal Reserve Bank of San Francisco or the Federal Reserve System. We thank Jeremy Berkowitz for comments as well as Emily Grimm for research assistance. 


\title{
Evaluating Covariance Matrix Forecasts in a Value-at-Risk Framework
}

\begin{abstract}
:
Covariance matrix forecasts of financial asset returns are an important component of current practice in financial risk management. A wide variety of models, ranging from matrices of simple summary measures to covariance matrices implied from option prices, are available for generating such forecasts. In this paper, we evaluate the relative accuracy of different covariance matrix forecasts using standard statistical loss functions and a value-at-risk (VaR) framework. This framework consists of hypothesis tests examining various properties of VaR models based on these forecasts as well as an evaluation using a regulatory loss function.

Using a foreign exchange portfolio, we find that implied covariance matrix forecasts appear to perform best under standard statistical loss functions. However, within the economic context of a VaR framework, the performance of VaR models depends more on their distributional assumptions than on their covariance matrix specification. Of the forecasts examined, simple specifications, such as exponentially-weighted moving averages of past observations, perform best with regard to the magnitude of VaR exceptions and regulatory capital requirements. These results provide empirical support for the commonly-used VaR models based on simple covariance matrix forecasts and distributional assumptions.
\end{abstract}




\section{Introduction}

The modeling of the second moments of asset returns has been a major field of study in finance over the last twenty years. Although regularities in the variances of asset returns were noted by Mandelbrot (1963), the explosion in volatility modeling can generally be traced to the work of Engle (1982) and Bollerslev (1986). ${ }^{1}$ Research in the area of volatility models has expanded in many directions and has led to a wide variety of modeling techniques, both univariate for individual assets and multivariate for asset portfolios.

Most of this research has focused on the in-sample fit of volatility models by proposing alternative model specifications and model diagnostic tools, such as the news-impact curve proposed by Engle and $\mathrm{Ng}$ (1993). A smaller amount of research has focused on the evaluation of out-of-sample volatility forecasts. These studies use forecast evaluation techniques to examine out-of-sample model performance in the hope of providing further guidance on model specification. In fact, model evaluations of this sort could be of greater practical importance since they can make specific recommendations to the users of volatility models. ${ }^{2}$

In this paper, we evaluate the out-of-sample performance of covariance matrix forecasts from multivariate volatility models based on different model specifications and information sets. The evaluation techniques used here and in the literature can generally be placed into two categories. The statistical category consists of loss functions based on distance measures, such as mean squared error. The economic category consists of techniques tied to specific uses of second moment forecasts, such as asset allocation, option trading and portfolio hedging. Although we use statistical techniques, we employ a value-at-risk (VaR) framework that should be more relevant to financial risk managers. For example, regulatory capital requirements for the market risk exposure of commercial banks are now explicitly based on VaR estimates and include an explicit penalty for model inaccuracy. ${ }^{3}$ Our goal is to provide insight on which covariance matrix forecasts generate the best performing VaR estimates from this perspective.

\footnotetext{
1 See Bollerslev, Engle and Nelson (1994) as well as Diebold and Lopez (1995) for detailed surveys.

2 See Diebold and Lopez (1996) for further discussion on forecast evaluation techniques.

3 See Basle Committee on Banking Supervision (1996a,b).
} 
The VaR framework we use consists of two sets of evaluation techniques. The first set focuses on the statistical properties of VaR estimates derived from VaR models based on alternative covariance matrix forecasts. Specifically, the binomial test of correct unconditional coverage, which is implicitly incorporated into the aforementioned bank capital requirements, is used to examine $1 \%, 5 \%, 10 \%$ and $25 \%$ VaR estimates. The test for correct conditional coverage developed by Christoffersen (1998) and multinomial extensions of these tests, which can examine several VaR estimates at the same time, are also used to examine these VaR estimates. Finally, the normal transform test developed by Berkowitz (1999) is used to evaluate the VaR models' forecasts of portfolio return distributions.

The second set of techniques focus on the magnitude of the losses experienced when VaR estimates are exceeded, clearly an issue of interest to financial institutions and their regulators. To determine whether the magnitudes of observed exceptions are in keeping with the model generating the VaR estimates, Berkowitz (1999) proposes a hypothesis test based on the truncated normal distribution. To examine the performance of the competing covariance matrix forecasts with respect to regulatory capital requirements, we use the regulatory loss function implied by the U.S. implementation of market risk amendment to the Basel Capital Accord. This loss function penalizes a VaR model for poor performance by using a capital charge multiplier based on the number of VaR exceptions; see Lopez (1999) for further discussion.

In this paper, we examine a portfolio of foreign exchange rates. With regard to the statistical loss functions, our results indicate that covariance matrix forecasts as implied from option prices appear to perform best. However, with respect to the more economically meaningful $\mathrm{VaR}$ framework, these forecasts do not perform as well. Our results for the testing of the competing VaR estimates' statistical properties indicate that the choice of the underlying distributional assumption for the VaR model is more important than that of the covariance matrix specification. In fact, only limited inference on the relative forecast performance of these specifications is available using these hypothesis tests.

However, the second set of VaR evaluation techniques do permit such inference. Specifically, the covariance matrix forecasts that perform best under these criteria are the naive specifications, such as exponentially-weighted moving averages of past observations. In fact, 
VaR estimates based on portfolio variance forecasts that completely ignore covariance matrix forecasts perform quite well under this criteria. For example, a simple VaR model based on an exponentially-weighted measure of portfolio variance and the standard normal distribution generates the lowest regulatory capital requirements. Overall, these empirical results provide evidence in support of the simple VaR models that are commonly used in practice.

The paper is structured as follows. Section II provides a short literature review of the statistical and economic evaluation of covariance matrix forecasts from multivariate volatility models. Section III describes the eight covariance matrix specifications and the statistical loss functions used in this study. Section IV describes the $40 \mathrm{VaR}$ models analyzed and presents the results for the first four sets of hypothesis tests that make up the VaR evaluation framework. Section V describes and presents the results for the final set of hypothesis tests and the regulatory loss function based on the quantity and magnitude of VaR exceedances. Section VI concludes.

\section{Literature Review}

As highlighted by Kroner and $\mathrm{Ng}$ (1998), the estimation of time-varying covariances and implicitly of the entire covariance matrix between asset returns is crucial for asset pricing, portfolio selection and risk management. To that end, a wide variety of multivariate volatility models have been proposed. For example, Bollerslev, Engle and Wooldridge (1988) proposed the diagonal GARCH model in which the individual variances and covariances are standard GARCH processes, and Engle and Kroner (1995) proposed the BEKK representation of the GARCH model, which more readily imposes the condition of positive definiteness on the estimated covariance matrices. In the field of risk management, exponentially-weighted moving averages of past portfolio returns are commonly used as a simple model of asset variances and covariances; see J.P. Morgan (1996). In addition, asset variances and covariances as implied from option prices are available for these purposes.

Given the wide variety of volatility models, a key question is how best to choose among them. Most studies evaluating the performance of volatility models have focused on the insample analysis of univariate models, although several have examined their out-of-sample 
performance using statistical and economic loss functions. ${ }^{4}$ A smaller number of studies have examined the in-sample and out-of-sample performance of multivariate volatility models using economic loss functions, particularly with respect to hedging strategies. For example, Cechetti, Cumby and Figlewski (1988) find that a time-varying covariance matrix is necessary in order to construct an optimal hedge ratio between Treasury bonds and bond futures, while Kroner and $\mathrm{Ng}$ (1998) find that the choice of multivariate volatility model can result in very different estimates of the optimal hedge ratio for a stock portfolio. ${ }^{5}$ Furthermore, Gibson and Boyer (1998) find that find standard time-series models produce better correlation forecasts than simple moving average models for the purpose of stock-index option pricing and trading.

With respect to financial risk management, current practice places much emphasis on value-at-risk (VaR) measures, which generally indicate the amount of portfolio value that could be lost over a given time period with a specified confidence level. ${ }^{6}$ A limited amount of research has been done to evaluate the forecast performance of multivariate volatility models within a VaR framework. For example, Hendricks (1996) provides the most extensive evaluation of alternative VaR models using a portfolio of foreign exchange rates, although he does not examine covariance forecasts. Several papers, such as Alexander and Leigh (1996), Jackson, Maude and Perraudin (1997) as well as Davé and Stahl (1996), examine VaR models for several asset portfolios using different multivariate volatility models. These comparisons are generally based on the number of $\mathrm{VaR}$ exceptions within observation periods mandated by bank regulators. In this paper, we examine VaR estimates from a much wider variety of multivariate volatility models, ranging from naive averages to standard time-series models to option-implied models.

4 See Pagan and Schwert (1990); Engle, Hong, Kane and Noh (1993); West, Edison and Cho (1993); West and Cho (1994); Engle, Kane and Noh (1996); Bollerslev and Ghysels (1996); Bollerslev and Mikkelsen (1996); and Lopez (2000).

5 For studies of optimal commodity hedges, see Baillie and Myers (1991); Myers (1991); and Bera, Garcia and Roh (1997). For studies of optimal foreign exchange futures hedges, see Kroner and Claessens (1991); Kroner and Sultan (1993); and Ghose and Kroner (1994). For studies of optimal interest rate futures hedges, see Park and Bera (1987); Cecchetti, Cumby and Figlewski (1988); and Gagnon and Lypny (1995). For studies of optimal stock index hedges, see Park and Switzer (1995); Tong (1996); and Kroner and Ng (1998). Chan, Kareski and Lakonishok (1999) examine various factor models for the covariance matrix of stock portfolio returns using portfolio measures such as the global minimum variance portfolio and minimum tracking error volatility.

6 See Jorion (1997) as well as Duffie and Pan (1997) for detailed surveys. 
Our evaluation is based purely on out-of-sample, covariance matrix forecasts and employs both statistical loss functions and a VaR framework that expands upon those in previous studies.

\section{Covariance Matrix Forecasts and Statistical Loss Functions}

\section{A. Covariance matrix forecasts}

In this paper, we examine the covariance matrix forecasts for a portfolio of foreign currencies. Specifically, we examine an equally-weighted dollar-denominated portfolio of the Deutschemark (DEM) and Japanese yen (JPY) over the period from January 3, 1980 to April 2, 1997. We use the in-sample period from January 3, 1980 to September 29, 1990 (2804 observations) to estimate the parameters of the multivariate models as needed, and we evaluate the models' one-step-ahead covariance matrix forecasts over the out-of-sample period from October 2, 1990 through April 2, 1997 (1679 observations).

Let $\mathrm{Y}_{\mathrm{t}+1}$ denote the $(2 \mathrm{x} 1)$ vector consisting of the DEM/USD and JPY/USD spot exchange rates, and $\mathrm{y}_{\mathrm{t}+1}=\ln \left(\mathrm{Y}_{\mathrm{t}+1}\right)$. Let $\Delta \mathrm{y}_{\mathrm{t}+1}$ be the first difference of $\mathrm{y}_{\mathrm{t}+1}$, which is the vector of exchange rate returns. Our analysis does not indicate the presence of any significant conditional mean dynamics in these series. ${ }^{7}$ Thus, we examine the model $\Delta y_{t+1}=\varepsilon_{t+1}$, where $\varepsilon_{t+1} \mid \Omega_{t} \sim D_{M}\left(0, H_{t+1}\right), D_{M}$ is a bivariate probability distribution and $H_{t+1}$ is the $(2 \times 2)$ matrix

$$
\mathrm{H}_{\mathrm{t}+1}=\left[\begin{array}{ll}
\mathrm{h}_{11, \mathrm{t}+1} & \mathrm{~h}_{12, \mathrm{t}+1} \\
\mathrm{~h}_{12, \mathrm{t}+1} & \mathrm{~h}_{22, \mathrm{t}+1}
\end{array}\right] .
$$

For our analysis, we impose the portfolio weighting vector $\mathrm{w}=[1,1]^{\prime}$, such that $\mathrm{x}_{\mathrm{t}+1}=\mathrm{w}^{\prime} \varepsilon_{\mathrm{t}+1}$ and $\mathrm{x}_{\mathrm{t}+1} \mid \Omega_{\mathrm{t}} \sim \mathrm{D}_{\mathrm{z}}\left(0, \mathrm{~h}_{\mathrm{pt}+1}\right)$, where $\mathrm{D}_{\mathrm{z}}$ is an univariate probability distribution and $\mathrm{h}_{\mathrm{pt}+1}=\mathrm{w}^{\prime} \mathrm{H}_{\mathrm{t}+1} \mathrm{w}$. Note that $\mathrm{x}_{\mathrm{t}+1}$ can be expressed as $\mathrm{x}_{\mathrm{t}+1}=\sqrt{\mathrm{h}_{\mathrm{pt}+1}} \mathrm{z}_{\mathrm{t}+1}$, where $\mathrm{z}_{\mathrm{t}+1} \sim \mathrm{D}(0,1)$.

${ }^{7}$ For both series, the in-sample mean is zero. The correlegram for the JPY series does not indicate any ARMA dynamics; i.e., the p-value for the portmanteau statistic is $12.3 \%$ at 20 lags and $38.8 \%$ at 40 lags. The correlegram for the DEM series indicates a small MA(6) effect; the p-value for the portmanteau statistic is $2.7 \%$ at 20 lags and $4.3 \%$ at 40 lags. Once this effect is removed, the p-value for the portmanteau statistic is $27.8 \%$ at 20 lags and $44.1 \%$ at 40 lags. However, given the uncommon nature of this MA term, we ignore it in our analysis. 
We examine three categories of covariance matrix forecasts: simple averages, time-series models and covariance matrices implied from option prices. The first category is based on different averages of the products of past exchange rate changes. The first specification is simply that the covariance matrix remains constant over the out-of-sample period and is equal to the insample period's unconditional covariance matrix; i.e., $\mathrm{H}_{\mathrm{t}+1}=\mathrm{C}=\left(\sum_{\mathrm{j}=1}^{2804} \varepsilon_{\mathrm{j}} \varepsilon_{\mathrm{j}}^{\prime}\right) / 2804$. We also consider two time-varying specifications that differ only in the weights applied in the averages. The historical average model equally weights the past 120 observations, such that $\mathrm{H}_{\mathrm{t}+1}=\left(\sum_{\mathrm{n}=0}^{119} \varepsilon_{\mathrm{t}-\mathrm{n}} \varepsilon_{\mathrm{t}-\mathrm{n}}^{\prime}\right) / 120 .{ }^{8}$ The exponentially-weighted moving average (EWMA) model is based on weights that decline exponentially; i.e., $H_{t+1}=(1-\lambda) \sum_{n=0}^{\infty} \lambda^{n} \varepsilon_{t-n} \varepsilon_{t-n}^{\prime}$ where $\lambda$ is a calibrated parameter. For our analysis, we chose $\lambda=0.94$, which is a commonly used value; see J.P. Morgan (1996) as well as Walter and Lopez (2000). ${ }^{9}$

The second category of covariance matrix forecasts consists of multivariate GARCH models. These models use the same information set as the first category, but impose specific forms of variance dynamics. The first model is specified as the bivariate $\operatorname{GARCH}(1,1)$ process suggested by Bollerslev, Engle and Wooldridge (1988), which is

$$
\left[\begin{array}{l}
h_{11, t+1} \\
h_{12, t+1} \\
h_{22, t+1}
\end{array}\right]=\left[\begin{array}{l}
\omega_{11} \\
\omega_{12} \\
\omega_{22}
\end{array}\right]+\left[\begin{array}{ccc}
\alpha_{11} & 0 & 0 \\
0 & \alpha_{12} & 0 \\
0 & 0 & \alpha_{22}
\end{array}\right]\left[\begin{array}{c}
\varepsilon_{1, t}^{2} \\
\varepsilon_{1, t} \varepsilon_{2, t} \\
\varepsilon_{2, t}^{2}
\end{array}\right]+\left[\begin{array}{ccc}
\beta_{11} & 0 & 0 \\
0 & \beta_{12} & 0 \\
0 & 0 & \beta_{22}
\end{array}\right]\left[\begin{array}{l}
h_{11, t} \\
h_{12, t} \\
h_{22, t}
\end{array}\right] .
$$

This specification suggests that the three components of $\mathrm{H}_{\mathrm{t}+1}$ each have separate time dynamics; we denote it as GARCH-DVEC. The second model is a bivariate $\mathrm{GARCH}(1,1)$ process using the BEKK specification suggested by Engle and Kroner (1998). This specification guarantees the positive definiteness of the fitted and forecasted covariance matrices without ignoring possible cross-variable interactions. For a lag order of one, the BEKK representation is

$$
\mathrm{H}_{\mathrm{t}+1}=\left[\begin{array}{cc}
\omega_{11}^{2} & 0 \\
\omega_{21} & \omega_{22}^{2}
\end{array}\right]\left[\begin{array}{cc}
\omega_{11}^{2} & \omega_{21} \\
0 & \omega_{22}^{2}
\end{array}\right]+\left[\begin{array}{ll}
\alpha_{11}^{2} & \alpha_{12} \\
\alpha_{21} & \alpha_{22}
\end{array}\right] \cdot\left[\begin{array}{cc}
\varepsilon_{1, \mathrm{t}}^{2} & \varepsilon_{1, \mathrm{t}} \varepsilon_{2, \mathrm{t}} \\
\varepsilon_{1, \mathrm{t}} \varepsilon_{2, \mathrm{t}} & \varepsilon_{2, \mathrm{t}}^{2}
\end{array}\right]\left[\begin{array}{ll}
\alpha_{11}^{2} & \alpha_{12} \\
\alpha_{21} & \alpha_{22}
\end{array}\right]+\left[\begin{array}{ll}
\beta_{11}^{2} & \beta_{12} \\
\beta_{21} & \beta_{22}
\end{array}\right] \cdot \mathrm{H}_{\mathrm{t}}\left[\begin{array}{ll}
\beta_{11}^{2} & \beta_{12} \\
\beta_{21} & \beta_{22}
\end{array}\right] ;
$$

${ }^{8}$ The choice of 120 days is based on previous studies; see Hendricks (1996) as well as Walter and Lopez (2000). This specification obviously could be generalized to $\mathrm{N}$ days.

${ }^{9}$ Foster and Nelson (1996) as well as Fleming et al. (2000) find similar values for the exponential decay parameter using nonparametric estimation techniques. 
we denote this specification as GARCH-BEKK. ${ }^{10}$ For both of these models, rolling estimation is used; that is, we more closely approximate actual forecasting practice by estimating the models' parameters using just the 1,000 observations prior to the date on which the forecast is made. ${ }^{11}$

The third category of covariance matrix forecasts we examine is based on the implied variances and covariances derived from option prices. ${ }^{12}$ Implied volatilities are derived from option prices by inverting the appropriate option pricing model, which is the Garman-Kohlhagen model (Garman and Kohlhagen, 1983) for foreign exchange options. This option pricing formula modifies the Black-Scholes model to account for foreign interest rates. An implied volatility can be interpreted as the market's assessment of the underlying asset's volatility over the remaining life of the option and is said to provide a "forward-looking" estimate of asset volatility. Thus, we examine such implied moments since they are based on different information sets than those used for the time-series models.

Implied covariance is defined as the covariance between two variables as implied by the price of a single option or the prices of several options. In our case, options on the exchange rates in currency trios are commonly traded, and the implied correlation between two exchange rates derived from implied volatilities is calculated as follows. ${ }^{13}$ Let $\mathrm{y}_{\mathrm{A} / \mathrm{B}, \mathrm{t}+1}$ represent the $\log$ of the daily exchange rate between currencies $\mathrm{A}$ and $\mathrm{B}$ at time $\mathrm{t}+1$. In terms of a third currency $\mathrm{C}$ and in the absence of arbitrage, $\mathrm{y}_{\mathrm{A} / \mathrm{B}, \mathrm{t}+1}=\mathrm{y}_{\mathrm{A} / \mathrm{C}, \mathrm{t}+1}-\mathrm{y}_{\mathrm{B} / \mathrm{C}, \mathrm{t}+1}$. Focusing on $\varepsilon_{\mathrm{A} / \mathrm{B}, \mathrm{t}+1}=\Delta \mathrm{y}_{\mathrm{A} / \mathrm{B}, \mathrm{t}+1}$, we have $\varepsilon_{\mathrm{A} / \mathrm{B}, \mathrm{t}+1}=\varepsilon_{\mathrm{A} / \mathrm{C}, \mathrm{t}+1}-\varepsilon_{\mathrm{B} / \mathrm{C}, \mathrm{t}+1}$. Since $\operatorname{Var}\left(\varepsilon_{\mathrm{A} / \mathrm{B}}\right)=\operatorname{Var}\left(\varepsilon_{\mathrm{A} / \mathrm{C}}\right)+\operatorname{Var}\left(\varepsilon_{\mathrm{B} / \mathrm{C}}\right)-2 \operatorname{Cov}\left(\varepsilon_{\mathrm{A} / \mathrm{C}}, \varepsilon_{\mathrm{B} / \mathrm{C}}\right)$, the implied covariance can be calculate from the three implied variance as

10 The lag order of one restricts the model in such a way that not as many vech (or diagonal) representations as possible are nested. Engle and Kroner (1993) state the necessary and sufficient conditions for achieving full generality within the BEKK model as well as for excluding the possibility of observationally equivalent representations.

11 The parameter estimates and in-sample diagnostics are available from the authors upon request.

12 The options prices used in this paper were provided by a prominent bank trading in the over-the-counter market for foreign exchange options. These implied volatilities are for at-the-money forward straddles, a combination of a European call option and a European put option with the strike prices set at the forward rate.

13 Note that Carr and Madan (1999) propose an alternative implied covariance forecast based on a synthetic covariance contract created by static positions in options on all three currency futures and dynamic trading in the underlying futures themselves. 


$$
\operatorname{Cov}_{\mathrm{IV}}\left(\varepsilon_{\mathrm{A} / \mathrm{C}}, \varepsilon_{\mathrm{B} / \mathrm{C}}\right)_{\mathrm{t}, \mathrm{T}}=\frac{1}{2}\left(\operatorname{Var}_{\mathrm{IV}}\left(\varepsilon_{\mathrm{A} / \mathrm{C}}\right)_{\mathrm{t}, \mathrm{T}}+\operatorname{Var}_{\mathrm{IV}}\left(\varepsilon_{\mathrm{B} / \mathrm{C}}\right)_{\mathrm{t}, \mathrm{T}}-\operatorname{Var}_{\mathrm{IV}}\left(\varepsilon_{\mathrm{A} / \mathrm{B}}\right)_{\mathrm{t}, \mathrm{T}}\right)
$$

Note that option maturities, denoted as T, are certainly longer than the one-step-ahead forecasts that we will be working with. However, since the option pricing model assumes that the second moments are constant over the life of the option, we generate one-day forecasts by assuming that the daily innovations are independent and dividing the implied variances by T. Further note that the $\mathrm{H}_{\mathrm{t}+1}$ forecast consisting of these implied second moments will be positive definite.

The other two implied model specifications we examine are based on combining certain implied moments with those from other specifications. It is commonly found that forecast performance can be improved by combining information sets. Although a model nesting both the time-series and option price information sets would be preferable, in this paper, we simply splice implied moments into the EWMA matrix. ${ }^{14}$ Specifically, we construct an $\mathrm{H}_{\mathrm{t}+1}$ series with implied variances and EWMA covariances and an $\mathrm{H}_{t+1}$ series with EWMA variances and implied covariances; these two covariance matrix specifications are denoted as EWMA-IVAR and EWMA-ICOV, respectively. Of course, these matrices are not guaranteed to be positive definite, and for our dataset, they are not $2 \%$ and $8 \%$ of the time, respectively. In such cases, we simply impose a zero covariance to insure positive definiteness.

The final set of forecasts we examine are not based on covariance matrix specifications at all. Zangari (1997) argues that a quicker and still useful approach to generating VaR measures is to ignore covariance matrix forecasts and focus on the time-varying volatility of the aggregate portfolio $\left(\mathrm{h}_{\mathrm{p}, \mathrm{t}+1}\right.$ in our notation). This approach significantly reduces the computational time needed to generate VaR measures without possibly reducing their overall accuracy. To examine this possibility, we examine the EWMA and the $\operatorname{GARCH}(1,1)$ specifications of the portfolio variance as alternative specifications of $h_{p, t+1}$ and denote them as port.EWMA and port.GARCH, respectively. These models provide another benchmark with which to evaluate covariance matrix forecasts; that is, whether they are necessary at all for generating accurate VaR measures.

14 Such an univariate, nested model is proposed by Kroner, Kneafsey and Claessens (1995) as well as Amin and $\mathrm{Ng}$ (1997). Manfredo et al. (1999) propose a simple combining technique based on linear regression. We have begun work along these lines for multivariate models. 


\section{B. Statistical Loss Functions}

Several statistical loss functions have been used to evaluate the out-of-sample forecast performance of univariate models; see Bollerslev and Ghysels (1996) for a short summary. In this paper, we use several loss functions to evaluate the two univariate volatility forecasts $h_{11, t+1}$ and $h_{22, t+1}$, the covariance forecast $h_{12, t+1}$ and the portfolio volatility forecast $h_{p, t+1}$.

The most commonly used loss function, mean-squared error (MSE), is defined as $\operatorname{MSE}_{x y}=\frac{1}{T} \sum_{j=1}^{T}\left(\varepsilon_{x, t+j} \varepsilon_{y, t+j}-h_{x y, t+j}\right)^{2}$, where $\varepsilon_{x, t+j}$ and $\varepsilon_{y, t+j}$ are the individual exchange rate returns and $h_{x y, t+j}$ is the forecast of interest. If $x=y$, then we are examining one of the two volatility forecasts, and if $\mathrm{x} \neq \mathrm{y}$, then we are examining the covariance forecast. For the portfolio variance, $\operatorname{MSE}_{\mathrm{p}}=\frac{1}{\mathrm{~T}} \sum_{\mathrm{j}=1}^{\mathrm{T}}\left(\mathrm{x}_{\mathrm{t}+\mathrm{j}}-\mathrm{h}_{\mathrm{p}, \mathrm{t}+\mathrm{j}}\right)^{2}$. Similarly, mean absolute error (MAE) loss function is defined as $\operatorname{MAE}_{x y}=\frac{1}{T} \sum_{j=1}^{T}\left|\varepsilon_{x, t+j} \varepsilon_{y, t+j}-h_{x y, t+j}\right|$ and $\operatorname{MAE}_{p}=\frac{1}{T} \sum_{j=1}^{T}\left|x_{p, t+j}-h_{p, t+j}\right|$.

The MSE and MAE loss functions penalize forecast errors symmetrically. Although this may be appropriate for covariance forecasts that may be negative, these loss functions are not as appropriate for variance forecasts, which should always be positive. Two loss functions that provide alternative asymmetric penalty functions are the logarithmic loss function, $\mathrm{LL}_{\mathrm{xy}}=\frac{1}{\mathrm{~T}} \sum_{\mathrm{j}=1}^{\mathrm{T}}\left(\ln \left(\varepsilon_{\mathrm{x}, \mathrm{t}+\mathrm{j}} \varepsilon_{\mathrm{y}, \mathrm{t}+\mathrm{j}}\right)-\ln \left(\mathrm{h}_{\mathrm{xy}, \mathrm{t}+\mathrm{j}}\right)\right)^{2}$, and the heteroskedasticity-adjusted MSE (HMSE), $\operatorname{HMSE}_{x y}=\frac{1}{\mathrm{~T}} \sum_{\mathrm{j}=1}^{\mathrm{T}}\left(\frac{\varepsilon_{x, t+\mathrm{j}} \varepsilon_{y, t+j}}{\mathrm{~h}_{\mathrm{x}, t+\mathrm{t}}}-1\right)^{2}$. Note that the LL loss function cannot be used for covariance forecasts because they may be negative. The LL loss function assigns proportionally higher weights to incorrect forecasts when the observed variance proxy is low. The final statistical loss function employed is based on the Gaussian quasi-maximum likelihood function commonly used to estimate GARCH models; i.e., $\mathrm{GMLE}_{\mathrm{xy}}=\frac{1}{\mathrm{~T}} \sum_{\mathrm{j}=1}^{\mathrm{T}}\left(\ln \left(\mathrm{h}_{\mathrm{xy}, t+\mathrm{j}}\right)+\frac{\varepsilon_{x, t+\mathrm{j}} \varepsilon_{y, t+j}}{\mathrm{~h}_{\mathrm{xy}, t+\mathrm{j}}}\right)$. Of course, for the portfolio returns, we substitute in the observed portfolio return $\mathrm{x}_{\mathrm{t}+1}$ and the forecasted portfolio variance $\mathrm{h}_{\mathrm{pt}+1}$.

Under a given loss function, the forecasts generating the lowest value can be said to be 
the most accurate. However, whether this outcome is statistically significant or an artifact of the dataset is not clear. Diebold and Mariano (1995) propose a statistical test of this hypothesis. For a particular loss function and second moment, we generate the time series of differences between the loss function values of a set of forecasts and the forecasts that minimized the loss function over the sample period. If the two forecasts perform equally well, then the mean of this difference should be zero. If we reject this null hypothesis, then the forecast with the lower loss function value is the more accurate forecast. The asymptotic Diebold-Mariano statistic is simply

$$
\mathrm{S}=\frac{\overline{\mathrm{d}}}{\sqrt{\hat{\sigma}_{\mathrm{d}}^{2} / \mathrm{T}}} \stackrel{\mathrm{a}}{\sim} \mathrm{N}(0,1),
$$

where $\overline{\mathrm{d}}$ is the sample mean of the difference series and $\hat{\sigma}_{\mathrm{d}}^{2}$ is a consistent estimate of its variance.

\section{Empirical results}

For our specified portfolio, the statistical loss function results are summarized in Table 1. Panels A and B show the results for the individual variance forecasts. For this dataset, the implied variances perform relatively well, especially under the MSE, HMSE and GMLE loss functions. In these six cases, the one-step-ahead implied forecasts significantly minimize the loss functions with respect to the other forecasts, except for the GMLE case for DEM variance forecasts. However, the statistical significance of this result varies across the two variances. For the JPY case, the null hypothesis of equal loss function values is clearly rejected for all competing forecasts, while for the DEM case, the null hypothesis is not as strongly rejected. Panel C presents the results for the covariance forecasts, which show that the implied forecasts again generally minimize the MSE, HMSE and GMLE loss functions in a significant way.

For the MAE and LL loss functions, the EWMA forecasts perform best as the minimizing forecasts in three of the four variance cases, but not always in a statistically significant way. In fact, GARCH-BEKK forecasts perform almost as well and are the minimizing covariance forecasts.

Panel D presents the results for the portfolio variance forecasts. Once again, the implied forecasts perform best for the MSE, HMSE and GMLE loss functions, although not in a 
consistently significant way. For the MAE and LL loss functions, the portfolio EWMA forecasts generate the lowest values, but only in the LL case is this result statistically significant. These results indicate that simple portfolio variance forecasts are useful under certain statistical loss functions, but that forecasts based on covariance matrix specifications generally perform as well or better.

In summary, statistical loss functions provide a useful, preliminary analysis of variance, covariance and portfolio variance forecasts. Our results indicate that the second moment forecasts implied by option prices generally outperform time-series forecasts for these loss functions, although the degree of statistical significance varies. Our findings are generally in line with those of Jorion (1995) for univariate exchange rates; see Figlewski (1997) for a survey of comparisons between implied and time-series forecasts. However, as suggested by Bollerslev et al. (1994) and Lopez (2000), economic loss functions that explicitly incorporate the costs faced by volatility forecast users provide the most meaningful forecast evaluations. In the next section, we examine the performance of the covariance matrix forecasts within a value-at-risk framework.

\section{Value-at-Risk Framework: Definitions, Models, Hypothesis Tests and Results}

\section{A. Definitions}

As discussed by Hsieh (1993), in the presence of volatility dynamics, conditional densities based on covariance matrix forecasts should provide a better description of short-term asset price movements than unconditional densities. This improved description could be particularly important for elements of financial risk management, such as hedge ratios and the capital allocations needed to cover possible portfolio losses. In this paper, we focus on value-atrisk (VaR) estimates, an increasingly common tool for financial risk management. Specifically, we examine the accuracy of several VaR models based on different covariance matrix specifications and conditional densities.

$\mathrm{VaR}$ models are characterized by their forecasted distributions of k-period-ahead portfolio returns. Generalizing our notation from before, let $\mathrm{x}_{\mathrm{t}+\mathrm{k}}$ denote the k-period-ahead portfolio return in $\log$ terms. Conditional on the information available at time $\mathrm{t}, \mathrm{x}_{\mathrm{t}+\mathrm{k}}$ is a random variable with distribution $\mathrm{f}_{\mathrm{t}+\mathrm{k}}$; that is, $\mathrm{x}_{\mathrm{t}+\mathrm{k}} \mid \Omega_{\mathrm{t}} \sim \mathrm{f}_{\mathrm{t}+\mathrm{k}}$. Thus, VaR model $\mathrm{m}$ is characterized by $\mathrm{f}_{\mathrm{mt}+\mathrm{k}}$, its 
forecast of $f_{t+k}$. A VaR estimate is a specified quantile of the forecasted return distribution over a given holding period. The $\mathrm{VaR}$ estimate at time $\mathrm{t}$ derived from model $\mathrm{m}$ for a k-period-ahead return, denoted $\operatorname{VaR}_{\mathrm{mt}}(\mathrm{k}, \alpha)$, is the critical value that corresponds to the lower $\alpha$ percent tail of $\mathrm{f}_{\mathrm{mt+k}}$. Thus, $\operatorname{VaR}_{\mathrm{mt}}(\mathrm{k}, \alpha)=\mathrm{F}_{\mathrm{mt}+\mathrm{k}}^{-1}(\alpha / 100)$, where $\mathrm{F}_{\mathrm{mt}+\mathrm{k}}^{-1}$ is the inverse of the cumulative distribution function corresponding to $\mathrm{f}_{\mathrm{m} t \mathrm{k}}$.

VaR estimates are now commonly used as measures of exposure to financial market fluctuations. In fact, under the auspices of the Basel Committee on Banking Supervision, the capital requirements for the market risk exposure of large banks are now explicitly based on their VaR estimates for a ten-day holding period $(\mathrm{k}=10)$ and 99 percent coverage $(\alpha=1)$. The formula for determining the capital requirements includes a multiplication factor that explicitly links the accuracy of the underlying VaR model to a bank's capital requirement. (This loss function is discussed further in section V.) Thus, a VaR framework should provide financial institutions with a meaningful economic framework in which to evaluate the accuracy of covariance matrix forecasts.

\section{B. Models}

VaR models can be used to generate distribution forecasts for k-step-ahead portfolio returns, but we examine one-step-ahead VaR estimates in accordance with common practice and our previous analysis. Let $\operatorname{VaR}_{\mathrm{mt}}(\alpha)$ denote the $\alpha \% \mathrm{VaR}$ estimate from model $\mathrm{m}$ generated at time $t$ for period $t+1$. Although $V a R$ models can be constructed in many ways, a common approach (and the one used in this paper) is to specify the variance dynamics $h_{p t+1}$ and the distributional form of $\mathrm{f}_{\mathrm{mt+1}}$ separately. ${ }^{15}$ In this analysis, we examine the eight covariance matrix specifications and two portfolio variance specifications from before and specify four different distributional forms for a total of $40 \mathrm{VaR}$ models.

15 The intuition for specifying a VaR model as a separate portfolio variance (whether based on a modeled covariance matrix or portfolio variance) and a distributional assumption arises from the two-step procedure proposed by Engle and Gonzalez-Rivera (1991). In that study, an univariate variance process was estimated under the normal assumption in order to generate standardized residuals, whose empirical distribution is then fitted using a nonparametric technique. We use a simplified version of their approach here. Note that an alternative approach is to estimate the parameters of a multivariate volatility model using a distributional form other than the multivariate normal. However, such distributional forms are difficult to specify and use in estimation. 
The first distributional form we examine is the standard normal, the one most commonly used for risk management purposes. The second distributional form is the t-distribution with an estimated number of degrees of freedom, which affects the tail thickness of the distribution. The $\mathrm{t}$-distribution is specified as

$$
\mathrm{f}_{\mathrm{m}}\left(\mathrm{x}_{\mathrm{t}+1}\right)=\Gamma\left(\frac{\mathrm{v}+1}{2}\right) \Gamma\left(\frac{\mathrm{v}}{2}\right)^{-1}\left((\mathrm{v}-2) \mathrm{h}_{\mathrm{pt}+1}\right)^{-1 / 2}\left(1+\mathrm{x}_{\mathrm{t}+1}^{2} \mathrm{~h}_{\mathrm{pt}+1}^{-1}(\mathrm{v}-2)^{-1}\right)^{-(\mathrm{v}-1) / 2},
$$

where $\mathrm{v}>2$ is the degrees of freedom. This parameter was estimated on the in-sample standardized residuals for the ten model specifications and was generally found to be approximately 13, which is the value used in the subsequent analysis.

The third distributional form is the generalized t-distribution, proposed by McDonald and Newey (1988) and used by Bollerslev, Engle and Nelson (1994). The generalized t-distribution has two shape parameters that directly influence the tail thickness and the width of the center of the distribution. This distribution is specified as

$$
f_{m}\left(x_{t+1}\right)=\frac{n}{2 h_{p t+1}^{1 / 2} q^{1 / n} B\left(\frac{1}{n}, q\right)\left(1+\left|x_{t+1}\right| /\left(q b^{n} h_{p t+1}^{n / 2}\right)\right)^{q+1 / n}},
$$

where $\mathrm{n}$ and $\mathrm{q}$ are the shape parameters, $\mathrm{n}>0, \mathrm{q}>0, \mathrm{nq}>2$, B is the beta function and $\mathrm{b}=(\Gamma(\mathrm{q}) \Gamma(1 / \mathrm{n}) / \Gamma(3 / \mathrm{n}) \Gamma(\mathrm{q}-2 / \mathrm{n}))^{1 / 2}$ is a scale factor that makes the conditional variance of $\mathrm{x}_{\mathrm{t}+1}$ equal $\mathrm{h}_{\mathrm{pt}+1}$. These shape parameters were estimated on the in-sample standardized residuals for the ten portfolio variances and were generally found to be approximately $n=2.5$ and $q=1$, which are the values used in the subsequent analysis. The last distributional form we examine is the simple, unsmoothed nonparametric distribution of portfolio returns, which is the distribution used in the so-called "historical simulation" approach for generating VaR estimates. Although nonparametric densities are available, we examine the unsmoothed distributions of the in-sample standardized residuals arising from the EWMA covariance matrix specification. We chose this model since it is commonly used for risk management purposes.

The VaR estimates corresponding to these VaR models are generated as follows. By definition, $\operatorname{Pr}\left(\mathrm{x}_{\mathrm{t}+1}<\mathrm{VaR}_{\mathrm{mt}}(\alpha)\right)=\alpha$, which is equivalent to 


$$
\operatorname{Pr}\left(\mathrm{z}_{\mathrm{pt}+1}<\frac{\operatorname{VaR}_{\mathrm{mt}}(\alpha)}{\sqrt{\mathrm{h}_{\mathrm{pt}+1}}}\right)=\mathrm{F}_{\mathrm{m}}\left(\operatorname{VaR}_{\mathrm{mt}}(\alpha) / \sqrt{\mathrm{h}_{\mathrm{pt}+1}}\right)=\alpha,
$$

where $\mathrm{F}_{\mathrm{m}}$ here denotes the cumulative distribution of the standardized residuals $\mathrm{z}_{\mathrm{pt+1}}$ under VaR model $\mathrm{m}$. Using the inverse of $\mathrm{F}_{\mathrm{m}}$, we have

$$
\operatorname{VaR}_{\mathrm{mt}}(\alpha) / \sqrt{\mathrm{h}_{\mathrm{pt}+1}}=\mathrm{F}_{\mathrm{m}}^{-1}(\alpha)
$$

or equivalently, $\operatorname{VaR}_{\mathrm{mt}}(\alpha)=\sqrt{\mathrm{h}_{\mathrm{pt}+1}} \mathrm{~F}_{\mathrm{m}}^{-1}(\alpha)$. Thus, the VaR estimates for our 40 models are based on the product of the forecasted portfolio standard deviations and the appropriate quantile from their assumed distributional form. Table 2 contains the quantiles for the four distributional assumptions used in this analysis.

\section{Hypothesis Tests and Empirical Results}

In this section, we describe the first three hypothesis tests used to evaluate the performance of the VaR models based on competing covariance matrix forecasts. The first two tests evaluate the unconditional and conditional $\alpha \%$ coverage of the competing sets of $\mathrm{VaR}$ estimates. In addition, we expand these binomial tests to multinomial form to simultaneously examine more elements of the VaR models' distribution forecasts. The fourth hypothesis test evaluates the entire distribution forecast using the models' empirical quantiles.

\section{1a). Evaluation of VaR estimates based on unconditional and conditional coverage}

Assuming that $\mathrm{VaR}$ estimates and their underlying model are accurate, exceptions or occasions when $\mathrm{x}_{\mathrm{t}+1}<\mathrm{VaR}_{\mathrm{mt}}(\alpha)$ can be modeled as independent draws from a binomial distribution with a probability of occurrence equal to $\alpha$ percent. Accurate VaR estimates should exhibit the property that their unconditional coverage $\alpha=\mathrm{x} / \mathrm{T}$, where $\mathrm{x}$ is the number of exceptions, equals $\alpha$ percent. The likelihood ratio statistic for testing whether $\hat{\alpha}=\alpha$ is

$$
\mathrm{LR}_{\mathrm{uc}}=2\left[\log \left(\hat{\alpha}^{\mathrm{x}}(1-\hat{\alpha})^{\mathrm{T}-\mathrm{x}}\right)-\log \left(\alpha^{\mathrm{x}} *(1-\alpha)^{\mathrm{T}-\mathrm{x}}\right)\right],
$$


which has an asymptotic $\chi^{2}(1)$ distribution. ${ }^{16}$

The $\mathrm{LR}_{\mathrm{uc}}$ test is an unconditional test of the coverage of $\mathrm{VaR}$ estimates since it simply counts exceptions over the entire period without reference to the information available at each point in time. However, if the underlying portfolio returns exhibit time-dependent heteroskedasticity, the conditional accuracy of $\mathrm{VaR}$ estimates is probably a more important issue. In such cases, VaR models that ignore such variance dynamics will generate VaR estimates that may have correct unconditional coverage, but at any given time, will have incorrect conditional coverage.

To address this issue, Christoffersen (1998) proposed conditional tests of VaR estimates based on interval forecasts. VaR estimates are essentially interval forecasts of the lower one percent tail of $f_{t+1}$, the one-step-ahead return distribution. The $\mathrm{LR}_{\mathrm{cc}}$ test used here is a test of correct conditional coverage. For a given VaR estimate, the indicator variable $\mathrm{I}_{\mathrm{mt}+1}$ for whether an exception occurred is constructed as

$$
\mathrm{I}_{\mathrm{mt}+1}=\left\{\begin{array}{l}
1 \text { if } \mathrm{x}_{\mathrm{t}+1}<\operatorname{VaR}_{\mathrm{mt}}(\alpha) \\
0 \text { if } \mathrm{x}_{\mathrm{t}+1} \geq \operatorname{VaR}_{\mathrm{mt}}(\alpha)
\end{array} .\right.
$$

Since accurate $\mathrm{VaR}$ estimates have correct conditional coverage, the $\mathrm{I}_{\mathrm{mt}+1}$ series must exhibit both correct unconditional coverage and serial independence. The $\mathrm{LR}_{\mathrm{cc}}$ test is a joint test of these properties, and the relevant test statistic is $\mathrm{LR}_{\mathrm{cc}}=\mathrm{LR}_{\mathrm{uc}}+\mathrm{LR}_{\mathrm{ind}}$, which is asymptotically distributed $\chi^{2}(2)$.

The $\mathrm{LR}_{\text {ind }}$ statistic is the likelihood ratio statistic for the null hypothesis of serial independence against the alternative of first-order Markov dependence. ${ }^{17}$ The likelihood function

16 The finite sample distribution of the $\mathrm{LR}_{\mathrm{uc}}$ statistic as well as the others in this study are of interest in actual practice; see Lopez (1999a,b). For example, with respect to size, the finite sample distribution of $\mathrm{LR}_{\mathrm{uc}}$ for specified $(\alpha, T)$ values may be sufficiently different from a $\chi^{2}(1)$ distribution that the asymptotic critical values may be inappropriate. As for the power of this test, Kupiec (1995) shows how this test has a limited ability to distinguish among alternative hypotheses and thus has low power in the typical samples of size 250 used for risk management purposes. However, since 1679 observations are used in this exercise, the asymptotic distributions for all of the test statistics are used.

17 As discussed in Christoffersen (1998), several other forms of dependence, such as second-order Markov dependence, can be specified. For the purposes of this paper, however, first-order Markov dependence is used. 
under this alternative hypothesis is $\mathrm{L}_{\mathrm{A}}=\left(1-\pi_{01}\right)^{\mathrm{T}_{00}} \pi_{01}^{\mathrm{T}_{01}}\left(1-\pi_{11}\right)^{\mathrm{T}_{10}} \pi_{11}^{\mathrm{T}_{11}}$, where the $\mathrm{T}_{\mathrm{ij}}$ notation denotes the number of observations in state $\mathrm{j}$ after having been in state $\mathrm{i}$ the period before, $\pi_{01}=\mathrm{T}_{01} /\left(\mathrm{T}_{00}+\mathrm{T}_{01}\right)$ and $\pi_{11}=\mathrm{T}_{11} /\left(\mathrm{T}_{10}+\mathrm{T}_{11}\right)$. Under the null hypothesis of independence, $\pi_{01}=\pi_{11}=\pi$, and the relevant likelihood function is $\mathrm{L}_{0}=(1-\pi)^{\mathrm{T}_{00}+\mathrm{T}_{10}} \pi^{\mathrm{T}_{01}+\mathrm{T}_{11}}$, where $\pi=\left(\mathrm{T}_{01}+\mathrm{T}_{11}\right) / 250$. The test statistic $\mathrm{LR}_{\text {ind }}=2\left[\log \mathrm{L}_{\mathrm{A}}-\log \mathrm{L}_{0}\right]$ has an asymptotic $\chi^{2}(1)$ distribution.

\section{1b). $L R_{u c}$ and $L R_{c c}$ test results for VaR estimates}

Table 3 reports the percentage of exceptions observed for each of the $40 \mathrm{VaR}$ models for the $1 \%, 5 \%, 10 \%$ and $25 \%$ VaR estimates over the entire out-of-sample period. These summary statistics are key components of the $\mathrm{LR}_{\mathrm{uc}}$ and $\mathrm{LR}_{\mathrm{cc}}$ test results reported in Table 4. Both the tables and the discussion below are framed with respect to the distributional assumption first and then with respect to the relative performance of the eight covariance matrix forecasts and two portfolio variance forecasts. Note that the $\mathrm{LR}_{\mathrm{uc}}$ and $\mathrm{LR}_{\mathrm{cc}}$ test results are qualitatively similar.

As shown in Panel A of Table 4, VaR models based on the standard normal distributional assumption perform relatively well at the lower quantiles (1\% and $5 \%)$ in that only a few forecasts fail the $\mathrm{LR}_{\mathrm{uc}}$ and $\mathrm{LR}_{\mathrm{cc}}$ tests at the 5\% significance level. However, almost all fail at the higher quantiles (10\% and 25\%). As shown in Panel B, VaR models based on the $\mathrm{t}(13)$ distributional assumption perform well only for the $1 \% \mathrm{VaR}$ estimates. This result indicates that the tail thickness of this distributional assumption probably limits its use to just the lowest VaR coverage levels.

The results for the $\mathrm{VaR}$ models based on estimated generalized t-distribution reported in Panel $\mathrm{C}$ indicate that all the covariance matrix specifications fail at the lowest quantile, but perform relatively well at the other quantiles. This result suggests that the overall shape of this distribution is better than the previous two, even though its lower $1 \%$ tail and the corresponding VaR estimates are inaccurate. The nonparametric distribution results in Panel D indicate that these VaR estimates basically do well across all four quantiles.

Although we can conclude that the two least restrictive distributional assumptions seem to produce better VaR estimates, inference regarding the relative forecast accuracy of the eight 
covariance matrix specifications and two portfolio variance specifications is limited. As shown in Panels A and B, no strong conclusions can be drawn across the forecasts using the normal or $\mathrm{t}(13)$ distributional assumptions. In addition, little inference is possible under the generalized $\mathrm{t}$ distribution for two reasons. First, for the $1 \%$ VaR estimates, all the VaR models have an exception rate that is too low due to the long lower tail of this distribution, and thus they fail the hypothesis tests. Second, for the three other quantiles, all the VaR models perform well, with the exception of the portfolio EWMA specification. Similarly, under the nonparametric distribution, most of the VaR models perform basically well, except for the constant and three implied covariance matrix specifications.

In summary, these results indicate that the dominant factor in determining the relative accuracy of VaR estimates with respect to coverage accuracy is the distributional assumption. The specifications of the covariance matrix forecasts appear to be of second-order importance. These results seem to provide support for the common industry practice of using the EWMA covariance matrix specification in generating VaR estimates. However, it does not completely explain why practitioners have generally settled on the standard normal distributional assumption. Although it did perform well for the lower coverage levels that are usually of interest, the nonparametric distribution did better across the four levels examined.

\section{2a). Multinomial form of the $L R_{u c}$ and $L R_{c c}$ tests}

By their very nature, VaR estimates focus specifically on just one quantile of the entire forecasted distribution. However, for VaR model evaluation, one could examine several of the model's VaR estimates at the same time. Such hypothesis tests provide a stricter test of coverage accuracy since it is based on more information than binomial tests. The generalization of binomial tests to multinomial tests is straightforward and is illustrated here for the trinomial case. Accurate VaR estimates should exhibit the property of unconditional coverage; i.e., $\left[\hat{\alpha}_{1}, \hat{\alpha}_{2}\right]=\left[\mathrm{x}_{1} / \mathrm{T}, \mathrm{x}_{2} / \mathrm{T}\right]=\left[\alpha_{1}, \alpha_{2}\right]$, where $\mathrm{x}_{1}$ and $\mathrm{x}_{2}$ are the number of exceptions for the first and second set of VaR estimates, respectively. The appropriate likelihood ratio statistic is

$$
\mathrm{LR}_{\mathrm{uc}}=2\left[\log \left(\hat{\alpha}_{1}^{\mathrm{x}_{1}} \hat{\alpha}_{2}^{\mathrm{x}_{2}}\left(1-\hat{\alpha}_{1}-\hat{\alpha}_{2}\right)^{\mathrm{T}-\mathrm{x}_{1}-\mathrm{x}_{2}}\right)-\log \left(\alpha_{1}^{\mathrm{x}_{1}} \alpha_{2}^{\mathrm{x}_{2}}\left(1-\alpha_{1}-\alpha_{2}\right)^{\mathrm{T}-\mathrm{x}_{1}-\mathrm{x}_{2}}\right)\right],
$$


which has an asymptotic $\chi^{2}(2)$ distribution. The trinomial $\mathrm{LR}_{\mathrm{cc}}$ statistic has a similar structure and an asymptotic $\chi^{2}(4)$ distribution.

\section{2b). Trinomial $L R_{\mathrm{uc}}$ and $L \mathbf{R}_{\mathrm{cc}}$ test results}

Table 5 presents the trinomial test results for two pairs of VaR estimates: the $1 \%$ and $5 \%$ VaR estimates, and the $1 \%$ and $10 \%$ VaR estimates. These results are basically in line with the univariate test results; the additional restrictions implied by the joint test should not and do not overturn the univariate results. For example, since all the VaR models under the $\mathrm{t}(13)$ assumption reject the binomial null hypotheses for the $5 \% \mathrm{VaR}$ estimates, all the joint [1\%, 5\%] tests reject the joint hypotheses as well. For the joint $[1 \%, 10 \%]$ tests, all of the VaR models based on the first three distributional assumptions strongly reject the joint null hypotheses, mainly due to the rejections of the binomial hypotheses by the $10 \% \mathrm{VaR}$ estimates for the normal and $\mathrm{t}(13)$ distributional assumptions and by the $1 \% \mathrm{VaR}$ estimates for the generalized- $\mathrm{t}$ assumption. However, under the nonparametric distributional assumption, several covariance matrix specifications do not reject the joint null hypothesis of the $\mathrm{LR}_{\mathrm{uc}}$ test since they do not strongly reject the two binomial null hypotheses.

The conformity of the trinomial results to the binomial results is to be expected. By testing the VaR estimates for additional properties, the trinomial tests provide a stricter analysis of the VaR models' distributional forecasts. Such analysis could be helpful to forecast users that are not exclusively interested in just one of the lower quantiles of the forecasted distributions. However, to fully examine the accuracy of the VaR models' distribution forecasts, we use the normal transform test proposed by Berkowitz (1999).

\section{3a). Evaluation of the forecasted distributions using the normal transform test}

Since VaR models are generally characterized by their distribution forecasts of portfolio returns, several authors have suggested that evaluations should be based directly on these forecasts. Such an evaluation would use all of the information available in the forecasts. The object of interest in these evaluation methods is the observed quantile $\mathrm{q}_{\mathrm{mt}+1}$, which is the quantile under the distribution forecast $\mathrm{f}_{\mathrm{mt}+1}$ in which the observed portfolio return $\mathrm{x}_{\mathrm{t}+1}$ actually falls; i.e., 


$$
\mathrm{q}_{\mathrm{mt}+1}\left(\mathrm{x}_{\mathrm{t}+1}\right)=\int_{-\infty}^{\mathrm{x}_{\mathrm{t}+1}} \mathrm{f}_{\mathrm{mt}+1}(\mathrm{x}) \mathrm{dx} .
$$

If the underlying VaR model is accurate, then its $\mathrm{q}_{\mathrm{mt}+1}$ series should be independent and uniformly distributed over the unit interval.

Several hypothesis tests have been proposed for testing these two properties. ${ }^{18}$ In this paper, we use the likelihood ratio test proposed by Berkowitz (1999). To examine whether the $\mathrm{q}_{\mathrm{mt+1}}$ series exhibits these properties, the $\mathrm{z}_{\mathrm{mt+1}}$ series is generated by transforming the $\mathrm{q}_{\mathrm{mt}+1}$ series with the inverse of the standard normal cumulative distribution function; i.e., $\mathrm{z}_{\mathrm{mt}+1}=\Phi^{-1}\left(\mathrm{q}_{\mathrm{mt}+1}\right)$. If the VaR model is correctly specified, the $\mathrm{z}_{\mathrm{mt}+1}$ series should be independent and identically distributed as standard normals. This hypothesis can be tested against alternative specifications, such as

$$
\mathrm{z}_{\mathrm{mt}+1}-\mu_{\mathrm{m}}=\rho_{\mathrm{m}}\left(\mathrm{z}_{\mathrm{mt}}-\mu_{\mathrm{m}}\right)+\eta_{\mathrm{t}+1},
$$

where the parameters $\left[\mu_{m}, \rho_{m}\right]$ are the conditional mean and $\operatorname{AR}(1)$ coefficient corresponding to the $\mathrm{z}_{\mathrm{mt}+1}$ series and $\eta_{\mathrm{t}+1}$ is a normal random variable with mean zero and variance $\sigma_{\mathrm{m}}^{2}$. Under the null hypothesis that both properties are present, $\left[\mu_{\mathrm{m}}, \rho_{\mathrm{m}}, \sigma_{\mathrm{m}}^{2}\right]=[0,0,1]$. The appropriate LR statistic is $\mathrm{LR}_{\mathrm{dist}}=2\left[\mathrm{~L}\left(\mu_{\mathrm{m}}, \rho_{\mathrm{m}}, \sigma_{\mathrm{m}}^{2}\right)-\mathrm{L}(0,0,1)\right]$, where

$$
\mathrm{L}\left(\mu_{\mathrm{m}}, \rho_{\mathrm{m}}, \sigma_{\mathrm{m}}\right)=-\frac{1}{2} \log \left(\frac{2 \pi \sigma_{\mathrm{m}}^{2}}{1-\rho_{\mathrm{m}}^{2}}\right)-\frac{\left(\mathrm{z}_{\mathrm{m} 1}-\frac{\mu_{\mathrm{m}}}{1-\rho_{\mathrm{m}}}\right)^{2}}{2 \sigma_{\mathrm{m}}^{2} /\left(1-\rho_{\mathrm{m}}^{2}\right)}-\frac{\mathrm{T}-1}{2} \log \left(2 \pi \sigma_{\mathrm{m}}^{2}\right)-\sum_{\mathrm{t}=1}^{\mathrm{T}-1} \frac{\left(\mathrm{z}_{\mathrm{mt}+1}-\mu_{\mathrm{m}}-\rho_{\mathrm{m}} \mathrm{z}_{\mathrm{mt}}\right)^{2}}{2 \sigma_{\mathrm{m}}^{2}}
$$

The $\mathrm{LR}_{\text {dist }}$ statistic is asymptotically distributed $\chi^{2}(3)$.

\section{3b). $L R_{\text {dist }}$ test results}

Table 6 contains the normal transform test results for the $40 \mathrm{VaR}$ models. The results generally indicate that the implied covariance matrix specifications perform poorly, regardless of the associated distributional assumption. Of the $12 \mathrm{VaR}$ models using these specifications, all

18 Crnkovic and Drachman (1996) suggest that these two properties be examined separately and thus propose two separate hypothesis tests. Diebold, Gunther and Tay (1998) propose the use of CUSUM statistics to test for these properties simultaneously. 
but two (the EWMA-IVAR specification under the generalized-t and nonparametric assumptions) reject the null hypothesis of correct distributional form. For the other VaR models, the null hypothesis is not generally rejected, except for the $t(13)$ distributional assumptions that performed poorly with respect to previous test results.

These results provide further evidence that the distributional assumption appears to drive these forecast evaluation results and that the covariance matrix specification is of secondary importance. In fact, other than the poor performance of the implied specifications, little inference on the relative performance of these models is possible. This poor performance may not be surprising given that implied volatilities are derived under the strict distributional assumptions underlying the Garman-Kohlhagen model and may not be directly applicable for use with other distributional assumptions. Furthermore, the basically equivalent performance of the covariance matrix specifications and the portfolio variance specifications that abstract from covariance matrix forecasts indicate that one may simplify the generation of VaR estimates in this way without sacrificing accuracy.

\section{Analysis of VaR Exception Magnitudes and Capital Requirements}

The evaluation of VaR models, both in practice and in the literature, has generally focused on the frequency of exceptions and thus has disregarded information on their magnitudes. However, as discussed by Hendricks (1996) and Berkowtiz (1999), the magnitudes of exceptions should be of primary interest to the various users of VaR models. For example, regarding bank capital requirements for market risk exposure, initial public documents stated that "[w]hen considering supervisory responses, [supervisory agencies] would take into account the extent to which trading losses exceed the VaR amounts, since exceptions that greatly exceed VaR amounts are of greater concern than are exceptions that exceed them only slightly." (Federal Register, 1996). In this section, we use two evaluation methods that focus on the magnitude of the losses experienced when VaR estimates are exceeded. The first method uses a hypothesis test developed by Berkowitz (1999) that explicitly examines the magnitude of VaR exceptions. The second method is based on the regulatory loss function embodied in current market risk capital requirements for large U.S. banks. These evaluation results permit inference on the 
relative performance of the various covariance matrix forecasts.

\section{1a). Normal transform magnitude test for VaR exceptions}

Berkowitz (1999) proposes a hypothesis test for determining whether the magnitude of observed VaR exceptions are consistent with the underlying VaR model. The key intuition is that $\mathrm{VaR}$ exceptions are treated as continuous random variables and not converted into the binary $\mathrm{I}_{\mathrm{mt}+1}$ variable used for the binomial and multinomial tests. For this test, we focus on the exceptions by treating non-exceptions as censored random variables. In essence, this test provides a middle ground between the full distribution approach of the $\mathrm{LR}_{\text {dist }}$ test and the frequency approach of the $\mathrm{LR}_{\mathrm{uc}}$ and $\mathrm{LR}_{\mathrm{cc}}$ tests.

As with the $\mathrm{LR}_{\text {dist }}$ test, the empirical quantile series is transformed into standard normal $\mathrm{z}_{\mathrm{mt}+1}$ series. However, the $\mathrm{z}_{\mathrm{mt}+1}$ values are treated as censored normal random variables, where the censoring is tied to the desired coverage level of the VaR estimates. Thus, $\mathrm{z}_{\mathrm{mt}+1}$ is transformed into $\gamma_{\mathrm{mt+1}}$ as follows:

$$
\gamma_{\mathrm{mt}+1}= \begin{cases}\mathrm{z}_{\mathrm{mt}+1} & \text { if } \mathrm{z}_{\mathrm{mt}+1}<\Phi^{-1}(\alpha) \\ 0 & \text { if } \mathrm{z}_{\mathrm{mt}+1} \geq \Phi^{-1}(\alpha)\end{cases}
$$

The conditional likelihood function for the right-censored observations of $\gamma_{\mathrm{mt}+1}=0$ (i.e., for nonexceptions) is

$$
\mathrm{f}\left(\gamma_{\mathrm{mt}+1} \mid \mathrm{z}_{\mathrm{mt}+1} \geq \Phi^{-1}(\alpha)\right)=1-\Phi\left(\frac{\Phi^{-1}(\alpha)-\mu_{\mathrm{m}}}{\sigma_{\mathrm{m}}}\right)
$$

where $\mu_{\mathrm{m}}$ and $\sigma_{\mathrm{m}}$ are the unconditional mean and standard deviation of the $\mathrm{z}_{\mathrm{mt}+1}$ series. ${ }^{19}$ The conditional likelihood function for $\mathrm{y}_{\mathrm{mt}+1}=\mathrm{z}_{\mathrm{mt+1}}$ is that of a truncated normal distribution; i.e.,

$$
\mathrm{f}\left(\gamma_{\mathrm{mt}+1} \mid \mathrm{z}_{\mathrm{mt}+1}<\Phi^{-1}(\alpha)\right)=\frac{\mathrm{f}\left(\mathrm{z}_{\mathrm{mt}+1}\right)}{\Phi\left(\frac{\Phi^{-1}(\alpha)-\mu_{\mathrm{m}}}{\sigma_{\mathrm{m}}}\right)}
$$

19 Note that this test does not examine the autocorrelation coefficient $\rho_{\mathrm{m}}$ discussed before, since the transformation $\mathrm{z}_{\mathrm{mt}+1}$ into the censored random variable $\mathrm{y}_{\mathrm{mt+1}}$ disrupts the time sequence of the series. Thus, we only examine the two unconditional moments of the $\mathrm{z}_{\mathrm{mt}+1}$ series. 
The unconstrained, conditional log-likelihood is

$\mathrm{f}_{\text {mag }}=\sum_{\gamma_{\mathrm{m}+1}=0} \log \left(1-\Phi\left(\frac{\Phi^{-1}(\alpha)-\mu_{\mathrm{m}}}{\sigma_{\mathrm{m}}}\right)\right)+\sum_{\mathrm{m}+1=z_{\mathrm{m}+1}}\left(-\frac{1}{2} \log \left(2 \pi \sigma_{\mathrm{m}}^{2}\right)-\frac{\left(\mathrm{y}_{\mathrm{mt}+1}-\mu_{\mathrm{m}}\right)^{2}}{2 \sigma_{\mathrm{m}}^{2}}-\log \left(\Phi\left(\frac{\Phi^{-1}(\alpha)-\mu_{\mathrm{m}}}{\sigma_{\mathrm{m}}}\right)\right)\right.$.

If the VaR model generating the empirical quantiles is correct, the $\gamma_{\mathrm{mt}+1}$ series should be identically distributed, and $\left[\mu_{\mathrm{m}}, \sigma_{\mathrm{m}}\right]$ should equal $[0,1]$. Thus, the relevant test statistic is $\mathrm{LR}_{\mathrm{mag}}=2\left[\mathrm{~L}_{\mathrm{mag}}\left(\mu_{\mathrm{m}}, \sigma_{\mathrm{m}}\right)-\mathrm{L}_{\mathrm{mag}}(0,1)\right]$, which is asymptotically distributed $\chi^{2}(2)$.

\section{1b). Results of the $\mathrm{LR}_{\text {mag }}$ test}

The results of the $\mathrm{LR}_{\mathrm{mag}}$ tests for the four sets of VaR estimates are reported in Table 7. Since this is a joint null hypothesis regarding the frequency of exceptions and their magnitudes, we expect that it would be rejected for the cases in which the VaR estimates rejected the binomial null hypothesis alone. This result occurs in only $82 \%$ of the cases (56 out of 68), but the bulk of the unexpected non-rejections of the joint null hypothesis ( 9 out of 12) occur for the $1 \% \mathrm{VaR}$ estimates, where the power of the binomial test is at its lowest. Overall, the two sets of test results were in agreement in $46 \%$ of the cases (73 out of 160), and the joint null hypothesis was rejected after the binomial null hypothesis was not rejected in another $47 \%$ of cases (75 of 160). Thus, the $\mathrm{LR}_{\text {mag }}$ results are consistent with the $\mathrm{LR}_{\mathrm{uc}}$ results in $93 \%$ of the cases.

Focusing first on the distributional assumptions underlying the VaR models, Panel C clearly indicates that, as before, the $\mathrm{t}(13)$ distributional assumption performs poorly, even for the $1 \% \mathrm{VaR}$ estimates for which it did well before. However, as shown in the other three panels of Table 7, the normal, generalized-t and nonparametric distributional assumptions perform relatively well for the $1 \% \mathrm{VaR}$ estimates.

Focusing on the different specifications of the portfolio variance forecasts, as with the $\mathrm{LR}_{\text {dist }}$ results, we find that the implied covariance matrix forecasts strongly reject the $\mathrm{LR}_{\text {mag }}$ null hypothesis in all 40 cases. Clearly, these covariance matrix forecasts perform poorly along many dimensions in a VaR framework, in contrast to their performance under the purely statistical loss functions. The covariance matrix specifications that performed best across the distributional assumptions are the historical and EWMA specifications, while the GARCH specifications do 
well only for the $1 \%$ coverage level.

In summary, although distributional assumptions play a role, the $\mathrm{LR}_{\text {mag }}$ test permits more inference on the covariance matrix forecasts and indicates that the simple average forecasts appear to perform best, further validating the current practice of financial institutions. The simple covariance matrix specifications performed better than the two portfolio variance specifications in that the latter's VaR estimates did not reject the joint null for only the lower coverage measures. However, this is only weak evidence in favor of using VaR models based in forecasted covariance matrices.

\section{2a). Capital requirements based on VaR estimates}

As mentioned before, current international bank regulations require that capital requirements for the market risk exposures of large banks be based on the banks' own VaR estimates. Lopez (1999) describes the U.S. implementation of these capital requirements and provides an explicit regulatory loss function that can be used to examine the relative performance of the $40 \mathrm{VaR}$ models. As before, we begin with the logged portfolio return

$$
\mathrm{x}_{\mathrm{t}+1}=\mathrm{w}^{\prime} \varepsilon_{\mathrm{t}+1}=\mathrm{w}^{\prime} \Delta \ln \left(\mathrm{Y}_{\mathrm{t}+1}\right)=\mathrm{w}_{1} \Delta \ln \left(\mathrm{Y}_{1 \mathrm{t}+1}\right)+\mathrm{w}_{2} \Delta \ln \left(\mathrm{Y}_{2 \mathrm{t}+1}\right) .
$$

In order to determine the dollar value of the foreign exchange portfolio, we have

$$
\mathrm{P} \$_{\mathrm{t}+1}=\ln \left(\mathrm{Y}_{\mathrm{t}+1}\right)=\mathrm{w}_{1} \ln \left(\mathrm{Y}_{1 \mathrm{t}+1}\right)+\mathrm{w}_{2} \ln \left(\mathrm{Y}_{2 \mathrm{t}+1}\right)=\ln \left(\mathrm{Y}_{1 \mathrm{t}+1}{ }^{\mathrm{w}_{1}} \mathrm{Y}_{2 \mathrm{t}+1}{ }^{\mathrm{w}_{2}}\right),
$$

which implies that $\mathrm{Y}_{t+1}=\mathrm{Y}_{1 \mathrm{t}+1}^{\mathrm{w}_{1}} \mathrm{Y}_{2 t+1}^{\mathrm{w}_{2}}$ and for our weighting vector [1,1], $\mathrm{Y}_{\mathrm{t}+1}=\mathrm{Y}_{1 t+1} \mathrm{Y}_{2 t+1}$. Note that a VaR estimate is expressed in dollar terms as the loss between the current portfolio value and the portfolio value corresponding to it; that is, $\operatorname{VaR}_{\mathrm{mt}}(\mathrm{k}, \alpha)$ is expressed in dollar terms as $\operatorname{VaR} \$_{m t}(k, \alpha)=P \$_{t}\left(1-e^{\operatorname{VaR}_{m t}(k, \alpha)}\right)$.

Under the current U.S. implementation of the market risk capital requirements, capital charges are based on VaR estimates generated using a ten-day holding period $(\mathrm{k}=10)$ and 99 percent coverage $(\alpha=1)$. In other words, a bank's market risk capital charge is based on its own estimate of the potential loss that would not be exceeded with one percent probability over the subsequent two week period. The actual market risk capital that must be hold for time $t+1$, denoted $\mathrm{MRC}_{\mathrm{mt}+1}$, is the larger of $\operatorname{VaR} \$_{\mathrm{mt}}(10,1)$ or a multiple of the average of the previous sixty $\operatorname{VaR} \$_{\mathrm{mt}}(10,1)$ estimates; that is, 


$$
\mathrm{MRC}_{\mathrm{mt}+1}=\max \left[\operatorname{VaR} \$_{\mathrm{mt}}(10,1) ; \mathrm{S}_{\mathrm{mt}} * \frac{1}{60} \sum_{\mathrm{i}=0}^{59} \mathrm{VaR}_{\mathrm{mt}-\mathrm{i}}(10,1)\right]+\mathrm{SR}_{\mathrm{mt}},
$$

where $\mathrm{S}_{\mathrm{mt}}$ and $\mathrm{SR}_{\mathrm{mt}}$ are a multiplication factor and an additional capital charge for the portfolio's idiosyncratic credit risk, respectively. In this study, we ignore the $\mathrm{SR}_{\mathrm{mt}}$ capital charge.

Under the current framework, $\mathrm{S}_{\mathrm{mt}} \geq 3$, and it is a step function that depends on the number of exceptions observed over the previous 250 trading days. ${ }^{20}$ The possible number of exceptions is divided into three zones. Within the green zone of four or fewer exceptions, a VaR model is deemed "acceptably accurate" to the regulators, and $\mathrm{S}_{\mathrm{mt}}$ remains at its minimum value of three. Within the yellow zone of five to nine exceptions, $S_{\mathrm{mt}}$ increases incrementally with the number of exceptions. ${ }^{21}$ Within the red zone of ten or more exceptions, the VaR model is deemed to be "inaccurate" for regulatory purposes, and $\mathrm{S}_{\mathrm{mt}}$ increases to its maximum value of four. The institution must also explicitly take steps to improve its risk management system. Thus, banks look to minimize exceptions (in order to minimize the multiplier) without reporting $\mathrm{VaR}$ estimates that are too large and raise the average term in the loss function.

\section{2b). Results}

As currently specified, this regulatory loss function is based on ten-day VaR estimates. However, since we are examining one-step-ahead covariance matrix forecasts, we evaluate oneday VaR estimates using this loss function. ${ }^{22}$ Table 8 presents the percentage of overlapping 250-day periods, of which there are 1430 in the out-of-sample period, for which a specific number of exceptions $(0, \leq 4, \leq 5, \leq 9, \leq 10)$ are observed for each of the 40 VaR models. Since in no case are there more than 10 exceptions, we are never in the red zone, and none of the models

\footnotetext{
20 Note that the portfolio returns reported to the regulators, commonly referred to as the "profit \& loss numbers", will usually not directly correspond to $\mathrm{x}_{\mathrm{t}+1}$. The profit \& loss numbers are usually polluted by the presence of customer fees and intraday trade results, which are not captured in standard VaR models. No definitive method of dealing with this discrepancy has been established.

21 In the yellow zone, the multiplier values for five through nine exceptions are $3.4,3.5,3.75$ and 3.85 , respectively.

22 A common approach for generating ten-day VaR estimates is to scaled up one-day VaR estimates using $\sqrt{10}$, which assumes that the portfolio returns are independent and identically distributed. We examined the performance of these simple ten-day VaR estimates under the regulatory loss function and not surprisingly found the results to be qualitatively similar.
} 
would invoke serious regulatory concerns.

Given the better performance of the EWMA-normal model in the previous sections, we chose its capital charges to be the standard against which the other models' capital charges are compared. Table 9 presents the percentage of the 1430 out-of-sample trading days for which the $\mathrm{MRC}_{\mathrm{m}, \mathrm{t+1}}$ capital charges for the EWMA-normal model are less than those of the other $39 \mathrm{VaR}$ models. This model clearly has lower capital requirements than all of the covariance matrix specifications under the $\mathrm{t}(13)$ and generalized-t distributions; that is, EWMA-normal perform better than these alternatives greater than $75 \%$ of the time. The only VaR estimates that generate smaller capital charges than those of the EWMA-normal model for more than 50\% of the trading days are those for the portfolio EWMA specification with the normal and the nonparametric distributions.

To more carefully examine these loss function results, we examine the differences between the capital charges for the EWMA-normal model and the other models using the Diebold-Mariano test statistic. The null hypothesis that we investigate is whether the mean difference between the two sets of capital charges is equal to zero. If we do not reject the null hypothesis, then the alternative model does not perform worse than the EWMA-normal model. If we reject the null hypothesis and the mean difference is negative, then the EWMA-normal model and its VaR estimates perform better because they generate lower capital charges on average. If we reject the null hypothesis and the mean difference is positive, then the alternative model and its VaR estimates perform better.

In Table 10, we present the p-values for the Diebold-Mariano statistics; if they are below $5 \%$, we reject the null hypothesis in favor of the EWMA-normal model, and if they are above $95 \%$, we reject the null hypothesis in favor of the alternative model. In 32 cases, we reject the null hypothesis in favor of the EWMA-normal model. We reject all the alternative VaR models based on the $t(13)$ and generalized-t distributional assumptions. For the nonparametric distribution, we do not reject the null hypothesis for the EWMA and portfolio EWMA specifications. For the normal distribution, several covariance matrix specifications do not reject the null hypothesis, indicating that they perform as well as the EWMA-normal model under this regulatory loss function. However, the most noteworthy case is the portfolio EWMA-normal 
model that rejects the null hypothesis in favor of itself; that is, the capital charges from the portfolio EWMA-normal model are, on average, significantly lower than those for the EWMAnormal model.

Table 11 presents the test results for the mean differences in capital charges between the portfolio EWMA-normal model and the other 39 VaR models. We reject the null hypothesis that the means are zero in all cases, which implies that the capital charges generated by the portfolio EWMA-normal model are the lowest in an economically and statistically meaningful way.

The empirical evaluation results under this regulatory loss function permit the most inference on the relative performance of the competing covariance matrix forecasts within a VaR framework. Under this loss function, the simple EWMA covariance matrix forecast performs quite well relative to the other alternatives, although the GARCH specifications also performs well under the normal distributional assumption. Thus, the use of simple covariance matrix forecasts can be justified in actual practice. However, overall, it can be argued that these results indicate that covariance matrix forecasts can be ignored in favor of portfolio variance forecasts for generating capital-minimizing VaR estimates.

\section{Conclusion}

In this paper, we evaluate the performance of several covariance matrix forecasts using standard statistical loss functions and a VaR framework, which should be more economically meaningful to financial risk managers. For a portfolio of foreign exchange rates, these evaluation results provide guidance on which covariance matrix forecasts perform best under these criteria. With respect to the statistical loss functions, our results indicate that the forecasts implied from option prices generally outperform forecasts based on simple averages and on GARCH models, although the degree of statistical significance varies. Our findings are generally in line with those of Jorion (1995) for univariate exchange rates. However, economic loss functions that explicitly incorporate the costs faced by forecast users provide the most meaningful forecast evaluations.

The economic context we use is a VaR framework consisting of two sets of evaluation techniques. The first set of techniques focuses on certain statistical properties of VaR estimates 
derived from the competing covariance matrix specifications. These results indicate that the dominant factor in determining the relative accuracy of VaR estimates is their distributional assumption, not the specification of the covariance matrix. Even though only a limited amount of inference is possible here, the implied covariance matrix specification performs poorly overall. This result may not be surprising given the many anomalies typically associated with implied volatilities. These results seem to provide support for the common industry practice of using the EWMA covariance matrix specifications in generating VaR estimates. However, it does not completely explain why practitioners have generally settled on the standard normal distributional assumption, since other distributional assumptions, such as using a nonparametric distribution, did better across the four quantiles examined.

The second set of evaluation techniques focus on the magnitude of losses experienced when VaR exceptions are registered. Although distributional assumptions play a role here as well, the normal transform magnitude test permits more inference on the performance of covariance matrix forecasts. The specifications that performed best overall are the historical and EWMA specifications, indicating that simple average forecasts appear to perform best and further validating the current practice of financial institutions. As with the full distribution test results, the implied covariance matrix forecasts reject the magnitude null hypothesis in all cases.

With respect to the regulatory loss function built into current bank capital requirements, the two VaR models that perform best are the port.EWMA-normal and the EWMA-normal model. This empirical result indicates that the VaR models based on the simplest specifications of second moment dynamics and distributional assumptions may be the ones that provide the capital-minimizing $\mathrm{VaR}$ forecasts. In fact, these results indicate that ignoring covariance matrix forecasts in favor of just portfolio variance forecasts may be preferable.

In short, from our empirical results, the covariance matrix forecasts that perform best overall within a VaR framework are those derived from simple specifications, such as the popular EWMA specification. Although this result challenges the folk wisdom that forecasts based on larger information sets, such as those embodied in options prices, or based on more rigorous time-series specification of their dynamics should be more accurate, our results indicate this additional information and structure is not necessarily helpful the purposes of VaR estimates. 
These empirical results are consistent with those of Lucas (2000), who finds that VaR models based on simple measures of portfolio variance and the normal distribution generate smaller discrepancies between actual and postulated VaR estimates than more sophisticated VaR models. $\mathrm{He}$ argues that this outcome is based on offsetting biases in the variance and VaR estimates of simple models that cannot be captured by more sophisticated models that attempt to capture the actual (but unknown) degree of leptokurtosis in the portfolio returns.

In fact, our results seem to go even further by indicating that $\mathrm{VaR}$ models based on covariance matrix forecasts for the individual portfolio assets do not perform much better than VaR models based just on the portfolio variance. Further research is necessary into why the additional information in the covariance matrix forecasts does not seem to be useful in this context and into whether it can be made useful by way of forecast combination techniques, as proposed by Christoffersen et al. (1998). 


\section{References}

Alexander, C.O. and Leigh, C.T., 1997. "On the Covariance Matrices Used in Value-at-Risk Models," Journal of Derivatives, Spring, 50-62.

Amin, K.I. and Ng, V.K., 1997. "Inferring Future Volatility from the Information in Implied Volatility in Eurodollar Options: A New Approach," Review of Financial Studies, 10, 333-367.

Basel Committee on Banking Supervision, 1996a. "Supervisory Framework for the Use of 'Backtesting' in Conjunction with the Internal Models Approach to Market Risk Capital Requirements," Report \#22, Bank for International Settlements.

Basel Committee on Banking Supervision, 1996b. "Amendment to the Capital Accord to Incorporate Market Risks,” Report \#24, Bank for International Settlements.

Bera, A.K., Garcia, P. and Roh, J.-S., 1997. "Estimation of Time-Varying Hedge Ratios for Corn and Soybeans: BGARCH and Random Coefficients Approaches," OFOR Paper Number 97-06, University of Illinois at Urbana-Champaign.

Berkowitz, J., 1999. "Evaluating the Forecasts of Risk Models," FEDS Discussion Paper \#11, Federal Reserve Board of Governors.

Baillie, R.T. and Myers, R.J., 1991. "Bivariate GARCH Estimation of the Optimal Commodity Futures Hedge," Journal of Applied Econometrics, 6, 109-124.

Bollerslev, T., 1986. "Generalized Autoregressive Conditional Heteroskedasticity," Journal of Econometrics, 31, 307-327.

Bollerslev, T., Engle, R.F. and Nelson, D.B., 1994. "ARCH Models,” in Engle, R.F. and McFadden, D., eds. The Handbook of Econometrics, Volume 4, 2959-3038. Amsterdam: North-Holland.

Bollerslev, T., Engle, R.F. and Wooldridge, J.M., 1988. “A Capital Asset Pricing Model with Time-Varying Covariances,” Journal of Political Economy, 96, 116-131.

Bollerslev, T. and Ghysels, E., 1996. "Periodic Autoregressive Conditional Heteroskedasticity," Journal of Business and Economic Statistics, 14, 139-157.

Bollerslev, T. and Mikkelsen, H.O., 1996. "Modeling and Pricing Long Memory in Stock Market Volatility," Journal of Econometrics, 73, 151-184.

Carr, P. and Madan, D., 1999. "Introducing the Covariance Swap," Risk, February, 47-51. 
Cecchetti, S.G., Cumby, R.E. and Figlewski, S., 1988. "Estimation of the Optimal Futures Hedge," Review of Economics and Statistics, 70, 623-630.

Chan, L.K.C., Karceski, J. and Lakonishok, J., 1999. “On Portfolio Optimization: Forecasting Covariances and Choosing the Risk Model," Review of Financial Studies, 12, 937-974.

Christoffersen, P.F., 1998. "Evaluating Interval Forecasts," International Economic Review, 39, 841-862.

Christoffersen, P.F., Hahn, J. and Inoue, A., 1998. "Testing, Comparing and Combining Valueat-Risk Measures," Manuscript, McGill University.

Crnkovic, C. and Drachman, J., 1996. “Quality Control,” Risk, 9, 139-143.

Davé, R.D. and Stahl, G., 1996. "On the Accuracy of VaR Estimates Based on the VarianceCovariance Approach,” Manuscript, German Federal Banking Supervisory Office.

Diebold, F.X., Gunther, T.A. and Tay, A.S., 1998. "Evaluating Density Forecasts with Applications to Financial Risk Management," International Economic Review, 39, 863883.

Diebold, F.X. and Lopez, J.A., 1995. "Modeling Volatility Dynamics," in Hoover, K., ed., Macroeconometrics: Developments, Tensions and Prospects, 427-466. Boston: Kluwer Academic Press.

Diebold, F.X. and Lopez, J.A., 1996. "Forecast Evaluation and Combination," in Maddala, G.S. and Rao, C.R., eds., Handbook of Statistics, Volume 14: Statistical Methods in Finance, 241-268. Amsterdam: North-Holland.

Diebold, F.X. and Mariano, R., 1995. "Comparing Predictive Accuracy," Journal of Business and Economic Statistics, 13, 253-264.

Duffie, D. and Pan, J., 1997. "An Overview of Value at Risk," The Journal of Derivatives, Spring, 7-49.

Engle, R.F., 1982. "Autoregressive Conditional Heteroskedasticity with Estimates of the Variance of U.K. Inflation," Econometrica, 50, 987-1008.

Engle, R.F. and Gonzalez-Rivera, G., 1991. "Semiparametric ARCH Models," Journal of Business and Economic Statistics, 9, 345-359.

Engle, R.F., Hong, C.-H., Kane, A. and Noh, J., 1993. “Arbitrage Valuation of Variance Forecasts with Simulated Options," in Chance, D.M. and Tripp, R.R., eds., Advances in 
Futures and Options Research, 393-415. Greenwich, CT: JIA Press.

Engle, R.F., Kane, A. and Noh, J., 1996. "Index-Option Pricing with Stochastic Volatility and the Value of Accurate Variance Forecasts," Review of Derivatives Research, 1, 139-158.

Engle, R.F. and Ng, V., 1993. "Measuring and Testing the Impact of News on Volatility," Journal of Finance, 48, 1749-1778.

Engle, R.F. and Kroner, K., 1995. "Multivariate Simultaneous Generalized ARCH," Econometric Theory, 11, 122-150.

Federal Register, 1996. "Risk-Based Capital Standards: Market Risk,” 61, 47357-47378.

Figlewski, S., 1997. "Forecasting Volatility," Financial Markets, Institutions and Instruments, $6,1-88$.

Fleming, J., Kirby, C. and Ostdiek, B., 2000. "The Economic Value of Volatility Timing," Journal of Finance, forthcoming.

Foster, D.P. and Nelson, D.B., 1996. “Continuous Record Asymptotics for Rolling Sample Variance Estimators," Econometrica, 64, 139-174.

Garman, M. B. and Kohlhagen, S.W., 1983. "Foreign Currency Option Values," Journal of International Money and Finance, 2, 231-237.

Gagnon, L. and Lypny, G., 1995. "Hedging Short-Term Interest Risk under Time-Varying Distributions," Journal of Futures Markets, 15, 767-783.

Ghose, D. and Kroner, K.F., 1994. "Common Persistence in Conditional Variances: Implications for Dynamic Hedging," Economic Working Paper \#94-1, University of Arizona.

Gibson, M.S. and Boyer, B.H., 1998. "Evaluating Forecasts of Correlation Using Option Pricing," The Journal of Derivatives, Winter, 18-38.

Hendricks, D., 1996. “Evaluation of Value-at-Risk Models Using Historical Data," Federal Reserve Bank of New York Economic Policy Review, 2, 39-69.

Hsieh, D.A., 1993. "Implications of Nonlinear Dynamics for Financial Risk Management," Journal of Financial and Quantitative Analysis, 28, 41-64.

Jackson, P., Maude, D.J. and Perraudin, W., 1997. "Bank Capital and Value at Risk," Journal of Derivatives, Spring, 73-89. 
Jorion, P., 1995. "Predicting Volatility in the Foreign Exchange Market", Journal of Finance, 50, 507-528.

Jorion, P., 1997. Value at Risk. Chicago: Irwin.

J.P. Morgan, 1996. J.P. Morgan/Reuters Riskmetrics ${ }^{T M}$ - Technical Document. New York: J.P. Morgan.

Kroner, K.F. and Claessens, S., 1991. "Optimal Dynamic Hedging Portfolios and the Currency Composition of External Debt," Journal of International Money and Finance, 10, 131148.

Kroner, K.F., Kneafsey, K.P. and Claessens, S., 1995. "Forecasting Volatility in Commodity Markets," Journal of Forecasting, 14, 77-95.

Kroner, K.F. and Ng, V.K., 1998. "Modeling Asymmetric Comovements of Asset Returns," The Review of Financial Studies, 11, 817-844.

Kroner, K.F. and Sultan, J., 1993. "Time-Varying Distributions and Dynamic Hedging with Foreign Currency Futures," Journal of Financial and Quantitative Analysis, 28, 535-551.

Kupiec, P., 1995. "Techniques for Verifying the Accuracy of Risk Measurement Models," Journal of Derivatives, 3, 73-84.

Lopez, J.A., 1999a. "Methods for Evaluating Value-at-Risk Estimates," Federal Reserve Bank of San Francisco Economic Review, 2, 3-15.

Lopez, J.A., 1999b. "Regulatory Evaluation of Value-at-Risk Models," 1999. Journal of Risk, 1, 37-64.

Lopez, J.A., 2000. "Evaluating the Predictive Accuracy of Volatility Models," Journal of Forecasting, forthcoming.

Lucas, A., 2000. "A Note on Optimal Estimation from a Risk-Management Perspective under Possibly Misspecified Tail Behavior,' Journal of Business and Economic Statistics, 18, 31-39.

Mandelbrot, B., 1963. “The Variation of Certain Speculative Prices,” Journal of Business, 36, 394-419.

Manfredo, M., Leuthold, R.M. and Irwin, S.H., 1999. "Forecasting Cash Price Volatility of Fed Cattle, Feeder Cattle and Corn: Time Series, Implied Volatility and Composite Approaches," OFOR Paper Number 99-08, Department of Agricultural and Consumer 
Economics, University of Illinois at Urbana-Champaign.

McDonald, J.B. and Newey, W.K., 1988. "Partially Adaptive Estimation of Regression Models via the Generalized t-Distribution," Econometric Theory, 4, 428-457.

Myers, R.J., 1991. "Estimating Time-Varying Optimal Hedge Ratios on Futures Markets," Journal of Futures Markets, 11, 39-53.

Pagan, A.R. and Schwert, G.W., 1990. "Alternative Models for Conditional Stock Volatility," Journal of Econometrics , 45, 267-290.

Park, H.Y. and Bera, A.K., 1987. "Interest-Rate Volatility, Basis Risk and Heteroskedasticity in Hedging Mortgages," AREUEA Journal, 15, 79-97.

Park, T.H. and Switzer, L.N., 1995. "Bivariate GARCH Estimation of the Optimal Hedge Ratios for Stock Index Futures: A Note," Journal of Futures Markets, 15, 61-67.

Tong, W.H.S., 1996. “An Examination of Dynamic Hedging,” Journal of International Money and Finance, 15, 19-35.

Walter, C.W. and Lopez, J.A., 2000. "Is Implied Correlation Worth Calculating? Evidence from Foreign Exchange Option Prices," Journal of Derivatives, 7(3), 65-82.

West, K.D. and Cho, D., 1994. "The Predictive Accuracy of Several Models of Exchange Rate Volatility," Journal of Econometrics, 69, 367-391.

West, K.D., Edison, H.J. and Cho, D., 1993. "A Utility-Based Comparison of Some Models of Exchange Rate Volatility," Journal of International Economics, 35, $23-45$.

Zangari, P., 1997. "Streamlining the Market Risk Measurement Process," RiskMetrics Monitor, $1,29-35$. 
Table 1. Evaluation Results under the Statistical Loss Functions

This analysis is based on the 1679 out-of-sample covariance matrix forecasts. The minimum value in each column is in bold font and underlined, and the second smallest value is just in bold font. The shaded cells indicate that the null hypothesis of equal loss function values between the forecast and the minimizing forecast is rejected using the Diebold-Mariano statistic. The asterisks indicate the degree of statistical significance (one for $10 \%$, two for 5\% and three for $1 \%)$.

Panel A. Variance forecasts for the daily DEM returns

\begin{tabular}{|l|l|l|l|l|l|}
\hline & MSE & MAE & HMSE & LL & GMLE \\
\hline Constant & $9.44168 \mathrm{e}-09^{* *}$ & $5.44717 \mathrm{e}-05$ & $4.17589^{* * *}$ & $9.70722^{*}$ & $-8.94005^{* * * *}$ \\
\hline Historical & $9.31532 \mathrm{e}-09^{* *}$ & $5.37523 \mathrm{e}-05$ & $4.30393^{* * *}$ & $9.29186^{*}$ & $-8.99659^{* *}$ \\
\hline EWMA & $9.00663 \mathrm{e}-09$ & $\underline{\mathbf{5 . 2 5 2 3 2 e - 0 5}}$ & $4.07639^{* * *}$ & $\underline{\mathbf{9 . 0 6 1 6 8}}$ & -9.03971 \\
\hline GARCH-DVEC & $8.93228 \mathrm{e}-09$ & $5.37428 \mathrm{e}-05^{* *}$ & $\mathbf{3 . 1 6 8 4 4}^{* * *}$ & $9.32334^{* *}$ & $\underline{\mathbf{9 . 0 4 8 6 4}}$ \\
\hline GARCH-BEKK & $\mathbf{8 . 9 0 6 1 7 e - 0 9}$ & $\mathbf{5 . 2 9 9 6 2 e - 0 5}$ & $3.33749^{* * *}$ & $\mathbf{9 . 2 5 7 7 3}^{*}$ & $\mathbf{- 9 . 0 4 6 5 6}$ \\
\hline Implied & $\underline{\mathbf{8 . 8 8 6 3 7 e - 0 9}}$ & $5.62076 \mathrm{e}-05^{* * *}$ & $\underline{\mathbf{2 . 4 1 1 9 3}}$ & $9.74525^{* * *}$ & -9.04463 \\
\hline
\end{tabular}

Panel B. Variance forecasts for the daily JPY returns

\begin{tabular}{|l|l|l|l|l|l|}
\hline & MSE & MAE & HMSE & LL & GMLE \\
\hline Constant & $9.39769 \mathrm{e}-09^{* *}$ & $4.94215 \mathrm{e}-05^{* *}$ & $4.95564^{*}$ & $9.75784^{* *}$ & $-9.08801^{* * *}$ \\
\hline Historical & $9.28328 \mathrm{e}-09^{* *}$ & $4.74357 \mathrm{e}-05$ & $6.66301^{* *}$ & $9.20758^{*}$ & $-9.11650^{* * *}$ \\
\hline EWMA & $9.12076 \mathrm{e}-09^{* * *}$ & $\mathbf{4 . 6 7 8 9 5 e - 0 5}$ & $6.45013^{* * *}$ & $\underline{\mathbf{8 . 9 9 8 8 8}}$ & $-9.15197^{* * *}$ \\
\hline GARCH-DVEC & $\mathbf{9 . 0 8 9 0 8 e - 0 9 * *}$ & $4.68262 \mathrm{e}-05$ & $\mathbf{4 . 8 7 1 4 4}^{* * *}$ & $\mathbf{9 . 1 7 6 0 0}$ & $\mathbf{- 9 . 1 6 9 0 7}^{* * *}$ \\
\hline GARCH-BEKK & $9.11594 \mathrm{e}-09^{* *}$ & $\underline{\mathbf{4 . 6 7 4 7 9 e - 0 5}}$ & $5.18208^{* * *}$ & 9.18913 & $-9.16038^{* * *}$ \\
\hline Implied & $\underline{\mathbf{8 . 8 9 4 9 5 e - 0 9}}$ & $4.86307 \mathrm{e}-05^{* * *}$ & $\underline{\underline{\mathbf{3 . 3 3 2 5 5}}}$ & $9.38747^{* * *}$ & $\underline{\mathbf{9 . 2 0 3 7 1}}$ \\
\hline
\end{tabular}

Panel C. Covariance forecasts for the daily DEM and JPY returns

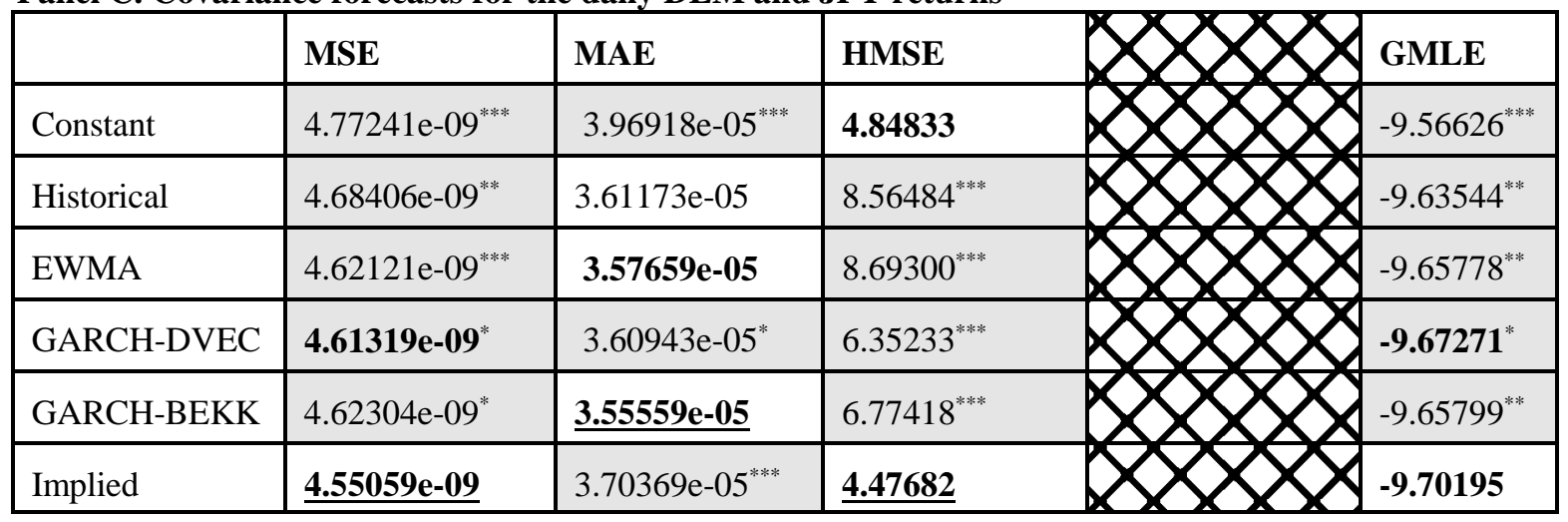


Panel D. Variance forecasts for the portfolio returns

\begin{tabular}{|l|l|l|l|l|l|}
\hline & MSE & MAE & HMSE & LL & GMLE \\
\hline Constant & $8.345 \times 10^{-8 * *}$ & $1.647 \times 10^{-4 *}$ & $3.526^{*}$ & $10.553^{* *}$ & $-7.869^{* * *}$ \\
\hline Historical & $8.255 \times 10^{-8 * *}$ & $1.560 \times 10^{-4}$ & $4.433^{* *}$ & $9.814^{*}$ & $-7.905^{* *}$ \\
\hline EWMA & $8.069 \times 10^{-8 * *}$ & $1.531 \times 10^{-4}$ & $4.135^{* * *}$ & $\mathbf{9 . 6 6 9}^{* *}$ & $-7.942^{*}$ \\
\hline GARCH-DVEC & $8.017 \times 10^{-8}$ & $1.547 \times 10^{-4}$ & $3.332^{* * *}$ & $9.935^{* * *}$ & -7.952 \\
\hline GARCH-BEKK & $8.021 \times 10^{-8}$ & $\mathbf{1 . 5 2 6} \times 10^{-4}$ & $3.498^{* * *}$ & $9.895^{* *}$ & -7.947 \\
\hline Implied & $\underline{\mathbf{7 . 9 2 3} \times 10^{-8}}$ & $1.611 \times 10^{-4 * *}$ & $\underline{\mathbf{2 . 4 9 7}}$ & $10.226^{* * *}$ & $\mathbf{- 7 . 9 6 2}$ \\
\hline EWMA-IVAR & $\mathbf{7 . 9 7 4} \times 10^{-8}$ & $1.564 \times 10^{-4 *}$ & $3.135^{* *}$ & $9.983^{* * *}$ & -7.959 \\
\hline EWMA-ICOV & $8.103 \times 10^{-8 * * *}$ & $1.655 \times 10^{-4 * * *}$ & $\mathbf{2 . 6 3 0}$ & $10.313^{* * *}$ & $-7.948^{*}$ \\
\hline Port. EWMA & $8.064 \times 10^{-8 * *}$ & $\underline{\mathbf{1 . 5 2 4} \times 10^{-4}}$ & $4.865^{* * *}$ & $\mathbf{9 . 5 2 5 0 0}$ & $-7.935^{*}$ \\
\hline Port. GARCH & $8.004 \times 10^{-8}$ & $1.531 \times 10^{-4}$ & $3.371^{* * *}$ & $9.884^{* *}$ & $\mathbf{- 7 . 9 5 5}$ \\
\hline
\end{tabular}

Table 2. Quantiles of the four distributional assumptions used

\begin{tabular}{|l|l|l|l|l|}
\hline & $\mathbf{N}(\mathbf{0 , 1})$ & $\mathbf{t}(\mathbf{1 3})$ & $\begin{array}{l}\text { generalized-t with } \\
{[\mathbf{n}, \mathbf{p}]=[\mathbf{2 . 5}, \mathbf{1}]}\end{array}$ & $\begin{array}{l}\text { nonparametric } \\
\text { based on EWMA } \\
\text { covariance matrix }\end{array}$ \\
\hline $1 \%$ & -2.3263 & -2.6503 & -3.2678 & -2.4468 \\
\hline $5 \%$ & -1.6449 & -1.7709 & -1.6157 & -1.6115 \\
\hline $10 \%$ & -1.2816 & -1.3502 & -1.1238 & -1.2066 \\
\hline $25 \%$ & -0.6745 & -0.6938 & -0.5405 & -0.5866 \\
\hline
\end{tabular}


Table 3. Observed Exception Rates for the 40 VaR Models

Panel A. VaR models based on the standard normal distributional assumption

\begin{tabular}{|l|l|l|l|l|}
\hline & \multicolumn{5}{|c|}{ Observed frequency of exceptions } \\
\hline $\begin{array}{l}\text { Covariance } \\
\text { specification }\end{array}$ & \multicolumn{1}{|c|}{$\mathbf{1 \%}$} & \multicolumn{1}{|c|}{$\mathbf{5 \%}$} & \multicolumn{1}{c|}{$\mathbf{1 0 \%}$} & \multicolumn{1}{c|}{$\mathbf{2 5 \%}$} \\
\hline Constant & 1.19 & 4.41 & 7.21 & 19.18 \\
\hline Historical & 1.85 & 5.30 & 8.22 & 21.80 \\
\hline EWMA & 1.67 & 5.18 & 7.86 & 21.62 \\
\hline GARCH-DVEC & 1.19 & 4.88 & 7.92 & 20.55 \\
\hline GARCH-BEKK & 1.19 & 4.76 & 8.16 & 20.85 \\
\hline Implied & 0.95 & 4.05 & 6.67 & 20.01 \\
\hline EWMA-IVAR & 1.19 & 4.35 & 7.21 & 20.55 \\
\hline EWMA-ICOV & 1.43 & 4.94 & 7.98 & 21.50 \\
\hline Port. EWMA & 1.55 & 5.54 & 8.93 & 22.51 \\
\hline Port. GARCH & 1.25 & 4.88 & 8.22 & 20.67 \\
\hline
\end{tabular}

Panel B. VaR models based on the $\mathbf{t}(13)$ distributional assumption

\begin{tabular}{|l|l|l|l|l|}
\hline & \multicolumn{5}{|c|}{ Observed frequency of exceptions } \\
\hline $\begin{array}{l}\text { Covariance } \\
\text { specification }\end{array}$ & $\mathbf{1 \%}$ & $\mathbf{5 \%}$ & $\mathbf{1 0 \%}$ & $\mathbf{2 5 \%}$ \\
\hline Constant & 0.89 & 3.63 & 6.67 & 18.58 \\
\hline Historical & 1.01 & 4.35 & 7.68 & 21.02 \\
\hline EWMA & 1.01 & 4.17 & 7.33 & 20.91 \\
\hline GARCH-DVEC & 0.77 & 3.75 & 7.44 & 19.77 \\
\hline GARCH-BEKK & 0.77 & 3.87 & 7.33 & 20.19 \\
\hline Implied & 0.54 & 3.16 & 6.02 & 19.24 \\
\hline EWMA-IVAR & 0.66 & 3.39 & 6.37 & 19.89 \\
\hline EWMA-ICOV & 0.95 & 4.05 & 7.27 & 21.08 \\
\hline Port. EWMA & 0.83 & 4.35 & 8.16 & 21.26 \\
\hline Port. GARCH & 0.71 & 3.69 & 7.39 & 20.37 \\
\hline
\end{tabular}


Panel C. VaR models based on the estimated generalized t-distributional assumption

\begin{tabular}{|l|l|l|l|l|}
\hline & \multicolumn{5}{|c|}{ Observed frequency of exceptions } \\
\hline $\begin{array}{l}\text { Covariance } \\
\text { specification }\end{array}$ & $\mathbf{1 \%}$ & $\mathbf{5 \%}$ & $\mathbf{1 0 \%}$ & $\mathbf{2 5 \%}$ \\
\hline Constant & 0.24 & 4.53 & 9.59 & 24.00 \\
\hline Historical & 0.42 & 5.36 & 11.14 & 25.97 \\
\hline EWMA & 0.30 & 5.36 & 11.26 & 26.92 \\
\hline GARCH-DVEC & 0.24 & 4.94 & 10.01 & 26.27 \\
\hline GARCH-BEKK & 0.30 & 4.94 & 10.01 & 26.15 \\
\hline Implied & 0.18 & 4.23 & 8.99 & 24.90 \\
\hline EWMA-IVAR & 0.30 & 4.53 & 9.35 & 25.61 \\
\hline EWMA-ICOV & 0.12 & 3.87 & 8.70 & 24.48 \\
\hline Port. EWMA & 0.48 & 5.66 & 11.49 & 27.87 \\
\hline Port. GARCH & 0.30 & 5.06 & 10.07 & 26.09 \\
\hline
\end{tabular}

Panel D. VaR models based on the in-sample nonparametric distributional assumption

\begin{tabular}{|l|l|l|l|l|}
\hline & \multicolumn{5}{|c|}{ Observed frequency of exceptions } \\
\hline $\begin{array}{l}\text { Covariance } \\
\text { specification }\end{array}$ & $\mathbf{1 \%}$ & $\mathbf{5 \%}$ & $\mathbf{1 0 \%}$ & $\mathbf{2 5 \%}$ \\
\hline Constant & 1.07 & 4.59 & 8.64 & 22.22 \\
\hline Historical & 1.67 & 5.36 & 9.11 & 24.30 \\
\hline EWMA & 1.31 & 5.36 & 9.41 & 25.07 \\
\hline GARCH-DVEC & 0.95 & 4.94 & 9.05 & 24.24 \\
\hline GARCH-BEKK & 1.07 & 5.00 & 8.99 & 24.42 \\
\hline Implied & 0.83 & 4.29 & 7.62 & 22.75 \\
\hline EWMA-IVAR & 0.89 & 4.59 & 8.34 & 23.29 \\
\hline EWMA-ICOV & 0.71 & 3.93 & 7.44 & 22.81 \\
\hline Port. EWMA & 1.25 & 5.66 & 10.18 & 25.43 \\
\hline Port. GARCH & 1.07 & 5.12 & 9.05 & 24.60 \\
\hline
\end{tabular}


Table 4. Asymptotic p-values for the $L R_{u c}$ and $L R_{\text {cc }}$ Test Results

The p-value for the $\mathrm{LR}_{\mathrm{uc}}$ and $\mathrm{LR}_{\mathrm{cc}}$ test statistics are reported. The $\mathrm{LR}_{\mathrm{uc}}$ statistics are asymptotically distributed $\chi^{2}(1)$, and the $\mathrm{LR}_{\mathrm{cc}}$ statistics are asymptotically distributed $\chi^{2}(2)$. The cells in bold font indicate rejection of the null hypothesis at the 5\% significance level.

Panel A. VaR models based on the standard normal distributional assumption

\begin{tabular}{|c|c|c|c|c|c|c|c|c|}
\hline \multirow[b]{3}{*}{$\begin{array}{l}\text { Covariance } \\
\text { specifcation }\end{array}$} & \multicolumn{8}{|c|}{ Binomial LR tests } \\
\hline & \multicolumn{2}{|c|}{$1 \%$ VaR estimates } & \multicolumn{2}{|c|}{$5 \%$ VaR estimates } & \multicolumn{2}{|c|}{$10 \%$ VaR estimates } & \multicolumn{2}{|c|}{$25 \%$ VaR estimates } \\
\hline & $\mathbf{L R}_{\mathrm{uc}}$ & $\mathbf{L R}_{\mathrm{cc}}$ & $\mathbf{L} \mathbf{R}_{\mathrm{uc}}$ & $\mathbf{L R}_{\mathrm{cc}}$ & $\mathbf{L R}_{\mathrm{uc}}$ & $\mathbf{L} \mathbf{R}_{\mathrm{cc}}$ & $\mathbf{L R}_{\mathrm{uc}}$ & $\mathbf{L R}_{\mathrm{cc}}$ \\
\hline Constant & 0.56 & 0.63 & 0.74 & 1.00 & 1.00 & 1.00 & 1.00 & 1.00 \\
\hline Historical & 1.00 & 0.99 & 0.42 & 0.85 & 0.99 & 1.00 & 1.00 & 0.99 \\
\hline EWMA & 0.99 & 0.97 & 0.27 & 0.87 & 1.00 & 1.00 & 1.00 & 1.00 \\
\hline $\begin{array}{l}\text { GARCH- } \\
\text { DVEC }\end{array}$ & 0.56 & 0.41 & 0.17 & 0.65 & 1.00 & 1.00 & 1.00 & 1.00 \\
\hline $\begin{array}{l}\text { GARCH- } \\
\text { BEKK }\end{array}$ & 0.56 & 0.41 & 0.34 & 0.87 & 0.99 & 1.00 & 1.00 & 1.00 \\
\hline Implied & 0.15 & 0.67 & 0.93 & 1.00 & 1.00 & 1.00 & 1.00 & 1.00 \\
\hline $\begin{array}{l}\text { EWMA- } \\
\text { IVAR }\end{array}$ & 0.56 & 0.63 & 0.79 & 0.98 & 1.00 & 1.00 & 1.00 & 1.00 \\
\hline $\begin{array}{l}\text { EWMA- } \\
\text { ICOV }\end{array}$ & 0.90 & 0.82 & 0.08 & 0.92 & 1.00 & 1.00 & 1.00 & 1.00 \\
\hline $\begin{array}{l}\text { Port. } \\
\text { EWMA }\end{array}$ & 0.94 & 0.92 & 0.68 & 0.72 & 0.86 & 0.86 & 0.98 & 0.97 \\
\hline $\begin{array}{l}\text { Port. } \\
\text { GARCH }\end{array}$ & 0.68 & 0.53 & 0.17 & 0.65 & 0.99 & 0.99 & 1.00 & 1.00 \\
\hline
\end{tabular}


Panel B. VaR models based on the $t(13)$ distributional assumption

\begin{tabular}{|c|c|c|c|c|c|c|c|c|}
\hline \multirow[b]{3}{*}{$\begin{array}{l}\text { Covariance } \\
\text { specifcation }\end{array}$} & \multicolumn{8}{|c|}{ Binomial LR tests } \\
\hline & \multicolumn{2}{|c|}{ 1\% VaR estimates } & \multicolumn{2}{|c|}{$5 \%$ VaR estimates } & \multicolumn{2}{|c|}{$10 \%$ VaR estimates } & \multicolumn{2}{|c|}{$25 \%$ VaR estimates } \\
\hline & $\mathbf{L} \mathbf{R}_{\mathrm{uc}}$ & $\mathbf{L R}_{\mathrm{cc}}$ & $\mathbf{L} \mathbf{R}_{\mathrm{uc}}$ & $\mathbf{L} \mathbf{R}_{\mathrm{cc}}$ & $\mathbf{L} \mathbf{R}_{\mathrm{uc}}$ & $\mathbf{L} \mathbf{R}_{\mathrm{cc}}$ & $\mathbf{L R}_{\mathrm{uc}}$ & $\mathbf{L R}_{\mathrm{cc}}$ \\
\hline Constant & 0.35 & 0.73 & 0.99 & 1.00 & 1.00 & 1.00 & 1.00 & 1.00 \\
\hline Historical & 0.04 & 0.16 & 0.79 & 0.98 & 1.00 & 1.00 & 1.00 & 1.00 \\
\hline EWMA & 0.04 & 0.16 & 0.89 & 0.99 & 1.00 & 1.00 & 1.00 & 1.00 \\
\hline $\begin{array}{l}\text { GARCH- } \\
\text { DVEC }\end{array}$ & 0.67 & 0.43 & 0.99 & 0.99 & 1.00 & 1.00 & 1.00 & 1.00 \\
\hline $\begin{array}{l}\text { GARCH- } \\
\text { BEKK }\end{array}$ & 0.67 & 0.43 & 0.97 & 0.99 & 1.00 & 1.00 & 1.00 & 1.00 \\
\hline Implied & 0.96 & 0.89 & 1.00 & 1.00 & 1.00 & 1.00 & 1.00 & 1.00 \\
\hline $\begin{array}{l}\text { EWMA- } \\
\text { IVAR }\end{array}$ & 0.87 & 0.70 & 1.00 & 1.00 & 1.00 & 1.00 & 1.00 & 1.00 \\
\hline $\begin{array}{l}\text { EWMA- } \\
\text { ICOV }\end{array}$ & 0.15 & 0.16 & 0.93 & 0.96 & 1.00 & 1.00 & 1.00 & 1.00 \\
\hline $\begin{array}{l}\text { Port. } \\
\text { EWMA }\end{array}$ & 0.52 & 0.31 & 0.79 & 0.85 & 0.99 & 0.99 & 1.00 & 1.00 \\
\hline $\begin{array}{l}\text { Port. } \\
\text { GARCH }\end{array}$ & 0.78 & 0.57 & 0.99 & 1.00 & 1.00 & 1.00 & 1.00 & 1.00 \\
\hline
\end{tabular}


Panel C. VaR models based on the generalized t-distributional assumption

\begin{tabular}{|c|c|c|c|c|c|c|c|c|}
\hline \multirow[b]{3}{*}{$\begin{array}{l}\text { Covariance } \\
\text { specifcation }\end{array}$} & \multicolumn{8}{|c|}{ Binomial LR tests } \\
\hline & \multicolumn{2}{|c|}{$1 \%$ VaR estimates } & \multicolumn{2}{|c|}{$5 \%$ VaR estimates } & \multicolumn{2}{|c|}{$10 \%$ VaR estimates } & \multicolumn{2}{|c|}{$25 \%$ VaR estimates } \\
\hline & $\mathbf{L R}_{\mathrm{uc}}$ & $\mathbf{L R}_{\mathrm{cc}}$ & $\mathbf{L} \mathbf{R}_{\mathrm{uc}}$ & $\mathbf{L} \mathbf{R}_{\mathrm{cc}}$ & $\mathbf{L R}_{\mathrm{uc}}$ & $\mathbf{L R}_{\mathrm{cc}}$ & $\mathbf{L} \mathbf{R}_{\mathrm{uc}}$ & $\mathbf{L} \mathbf{R}_{\mathrm{cc}}$ \\
\hline Constant & 1.00 & 1.00 & 0.63 & 0.99 & 0.43 & 0.96 & 0.66 & 0.59 \\
\hline Historical & 0.99 & 0.98 & 0.50 & 0.85 & 0.87 & 0.86 & 0.64 & 0.50 \\
\hline EWMA & 1.00 & 1.00 & 0.50 & 0.97 & 0.91 & 0.78 & 0.93 & 0.81 \\
\hline $\begin{array}{l}\text { GARCH- } \\
\text { DVEC }\end{array}$ & 1.00 & 1.00 & 0.08 & 0.81 & 0.01 & 0.30 & 0.77 & 0.52 \\
\hline $\begin{array}{l}\text { GARCH- } \\
\text { BEKK }\end{array}$ & 1.00 & 1.00 & 0.08 & 0.81 & 0.01 & 0.30 & 0.72 & 0.47 \\
\hline Implied & 1.00 & 1.00 & 0.86 & 1.00 & 0.84 & 0.88 & 0.08 & 0.12 \\
\hline $\begin{array}{l}\text { EWMA- } \\
\text { IVAR }\end{array}$ & 1.00 & 1.00 & 0.63 & 0.98 & 0.63 & 0.67 & 0.44 & 0.25 \\
\hline $\begin{array}{l}\text { EWMA- } \\
\text { ICOV }\end{array}$ & 1.00 & 1.00 & 0.97 & 1.00 & 0.93 & 0.96 & 0.38 & 0.30 \\
\hline $\begin{array}{l}\text { Port. } \\
\text { EWMA }\end{array}$ & 0.98 & 0.95 & 0.77 & 0.85 & 0.95 & 0.88 & 0.99 & 0.97 \\
\hline $\begin{array}{l}\text { Port. } \\
\text { GARCH }\end{array}$ & 1.00 & 1.00 & 0.09 & 0.55 & 0.07 & 0.27 & 0.69 & 0.42 \\
\hline
\end{tabular}


Panel D. VaR models based on the nonparametric distributional assumption

\begin{tabular}{|l|l|l|l|l|l|l|l|l|}
\hline & \multicolumn{7}{|c|}{ Binomial LR tests } \\
\hline & $\mathbf{1 \%}$ VaR estimates & \multicolumn{1}{|c|}{$\mathbf{5 \%}$ VaR estimates } & \multicolumn{1}{|l|}{$\mathbf{1 0 \%}$ VaR estimates } & \multicolumn{2}{|l|}{$\mathbf{2 5 \%}$ VaR estimates } \\
\hline $\begin{array}{l}\text { Covariance } \\
\text { specifcation }\end{array}$ & $\mathbf{L R}_{\text {uc }}$ & $\mathbf{L R}_{\mathrm{cc}}$ & $\mathbf{L} \mathbf{R}_{\mathrm{uc}}$ & $\mathbf{L R}_{\mathrm{cc}}$ & $\mathbf{L R}_{\mathrm{uc}}$ & $\mathbf{L R}_{\mathrm{cc}}$ & $\mathbf{L R}_{\mathbf{u c}}$ & $\mathbf{L R}_{\mathrm{cc}}$ \\
\hline Constant & 0.23 & 0.60 & 0.57 & $\mathbf{0 . 9 9}$ & 0.94 & $\mathbf{0 . 9 8}$ & $\mathbf{0 . 9 9}$ & $\mathbf{0 . 9 8}$ \\
\hline Historical & $\mathbf{0 . 9 9}$ & $\mathbf{0 . 9 7}$ & 0.50 & 0.85 & 0.78 & 0.93 & 0.49 & 0.24 \\
\hline EWMA & 0.78 & 0.65 & 0.50 & $\mathbf{0 . 9 7}$ & 0.58 & 0.73 & 0.06 & 0.09 \\
\hline $\begin{array}{l}\text { GARCH- } \\
\text { DVEC }\end{array}$ & 0.15 & 0.16 & 0.08 & 0.81 & 0.81 & 0.91 & 0.53 & 0.26 \\
\hline $\begin{array}{l}\text { GARCH- } \\
\text { BEKK }\end{array}$ & 0.23 & 0.21 & 0.00 & 0.79 & 0.84 & 0.93 & 0.42 & 0.24 \\
\hline Implied & 0.52 & 0.79 & 0.83 & $\mathbf{0 . 9 9}$ & $\mathbf{1 . 0 0}$ & $\mathbf{1 . 0 0}$ & $\mathbf{0 . 9 7}$ & 0.94 \\
\hline $\begin{array}{l}\text { EWMA- } \\
\text { IVAR }\end{array}$ & 0.35 & 0.21 & 0.57 & $\mathbf{0 . 9 7}$ & $\mathbf{0 . 9 8}$ & $\mathbf{0 . 9 9}$ & 0.90 & 0.80 \\
\hline $\begin{array}{l}\text { EWMA- } \\
\text { ICOV }\end{array}$ & 0.78 & 0.57 & $\mathbf{0 . 9 6}$ & $\mathbf{0 . 9 9}$ & $\mathbf{1 . 0 0}$ & $\mathbf{1 . 0 0}$ & $\mathbf{0 . 9 6}$ & 0.93 \\
\hline $\begin{array}{l}\text { Port. } \\
\text { EWMA }\end{array}$ & 0.68 & 0.53 & 0.77 & 0.85 & 0.20 & 0.52 & 0.32 & 0.09 \\
\hline $\begin{array}{l}\text { Port. } \\
\text { GARCH }\end{array}$ & 0.23 & 0.21 & 0.18 & 0.53 & 0.81 & 0.91 & 0.30 & 0.11 \\
\hline
\end{tabular}


Table 5. Asymptotic p-values for the Trinomial $L R_{u c}$ and $L R_{c c}$ Test Results The p-value for the trinomial $\mathrm{LR}_{\mathrm{uc}}$ and $\mathbf{L R c c}$ test statistic are reported. The trinomial $\mathrm{LR}_{\mathrm{uc}}$ statistics are asymptotically distributed $\chi^{2}(2)$, and the trinomial $\operatorname{LR}_{\mathrm{cc}}$ statistics are asymptotically distributed $\chi^{2}(4)$. The shaded cells indicate rejection of the null hypothesis at the 5\% significance level.

Panel A. VaR models based on the standard normal distributional assumption

\begin{tabular}{|l|l|l|l|l|}
\hline & \multicolumn{2}{|l|}{ Test statistics for $\alpha=[\mathbf{0 . 0 1}, \mathbf{0 . 0 5}]$} & \multicolumn{2}{l|}{ Test statistics for $\alpha=[\mathbf{0 . 0 1 , 0 . 1 0 ]}$} \\
\hline $\begin{array}{l}\text { Covariance } \\
\text { specification }\end{array}$ & $\mathbf{L} \mathbf{R}_{\mathrm{uc}}$ & $\mathbf{L} \mathbf{R}_{\mathrm{cc}}$ & $\mathbf{L} \mathbf{R}_{\mathrm{uc}}$ & $\mathbf{L R}_{\mathrm{cc}}$ \\
\hline Constant & 0.60 & $\mathbf{1 . 0 0}$ & $\mathbf{1 . 0 0}$ & $\mathbf{1 . 0 0}$ \\
\hline Historical & $\mathbf{0 . 9 9}$ & $\mathbf{1 . 0 0}$ & $\mathbf{1 . 0 0}$ & $\mathbf{1 . 0 0}$ \\
\hline EWMA & $\mathbf{0 . 9 6}$ & $\mathbf{1 . 0 0}$ & $\mathbf{1 . 0 0}$ & $\mathbf{1 . 0 0}$ \\
\hline GARCH-DVEC & 0.27 & $\mathbf{1 . 0 0}$ & $\mathbf{0 . 9 9}$ & $\mathbf{1 . 0 0}$ \\
\hline GARCH-BEKK & 0.32 & $\mathbf{1 . 0 0}$ & $\mathbf{0 . 9 7}$ & $\mathbf{1 . 0 0}$ \\
\hline Implied & 0.82 & $\mathbf{1 . 0 0}$ & $\mathbf{1 . 0 0}$ & $\mathbf{1 . 0 0}$ \\
\hline EWMA-IVAR & 0.65 & $\mathbf{1 . 0 0}$ & $\mathbf{1 . 0 0}$ & $\mathbf{1 . 0 0}$ \\
\hline EWMA-ICOV & 0.75 & $\mathbf{1 . 0 0}$ & $\mathbf{0 . 9 9}$ & $\mathbf{1 . 0 0}$ \\
\hline Port. EWMA & 0.94 & $\mathbf{1 . 0 0}$ & $\mathbf{0 . 9 7}$ & $\mathbf{1 . 0 0}$ \\
\hline Port. GARCH & 0.40 & $\mathbf{1 . 0 0}$ & $\mathbf{0 . 9 6}$ & $\mathbf{1 . 0 0}$ \\
\hline
\end{tabular}

Panel B. VaR models based on the $t(13)$ distributional assumption

\begin{tabular}{|c|c|c|c|c|}
\hline \multirow[b]{2}{*}{$\begin{array}{l}\text { Covariance } \\
\text { specification }\end{array}$} & \multicolumn{2}{|c|}{ Test statistics for $\alpha=[0.01,0.05]$} & \multicolumn{2}{|c|}{ Test statistics for $\alpha=[0.01,0.10]$} \\
\hline & $\mathbf{L R}_{\mathrm{uc}}$ & $\mathbf{L R}_{\mathrm{cc}}$ & $\mathbf{L R}_{\mathrm{uc}}$ & $\mathbf{L} \mathbf{R}_{\mathrm{cc}}$ \\
\hline Constant & 0.98 & 1.00 & 1.00 & 1.00 \\
\hline Historical & 0.54 & 1.00 & 1.00 & 1.00 \\
\hline EWMA & 0.72 & 1.00 & 1.00 & 1.00 \\
\hline GARCH-DVEC & 0.97 & 1.00 & 1.00 & 1.00 \\
\hline GARCH-BEKK & 0.95 & 1.00 & 1.00 & 1.00 \\
\hline Implied & 1.00 & 1.00 & 1.00 & 1.00 \\
\hline EWMA-IVAR & 1.00 & 1.00 & 1.00 & 1.00 \\
\hline EWMA-ICOV & 0.82 & 1.00 & 1.00 & 1.00 \\
\hline Port. EWMA & 0.65 & 1.00 & 0.97 & 1.00 \\
\hline Port. GARCH & 0.98 & 1.00 & 1.00 & 1.00 \\
\hline
\end{tabular}


Panel C. VaR models based on the generalized t-distributional assumption

\begin{tabular}{|l|l|l|l|l|}
\hline & \multicolumn{2}{|l|}{ Test statistics for $\alpha=[0.01,0.05]$} & \multicolumn{2}{l|}{ Test statistics for $\alpha=[0.01,0.10]$} \\
\hline $\begin{array}{l}\text { Covariance } \\
\text { specification }\end{array}$ & $\mathbf{L R}_{\mathrm{uc}}$ & $\mathbf{L} \mathbf{R}_{\mathrm{cc}}$ & $\mathbf{L} \mathbf{R}_{\mathrm{uc}}$ & $\mathbf{L R}_{\mathrm{cc}}$ \\
\hline Constant & 1.00 & 1.00 & 1.00 & 1.00 \\
\hline Historical & 1.00 & 1.00 & 1.00 & 1.00 \\
\hline EWMA & 1.00 & 1.00 & 1.00 & 1.00 \\
\hline GARCH-DVEC & 1.00 & 1.00 & 1.00 & 1.00 \\
\hline GARCH-BEKK & 1.00 & 1.00 & 1.00 & 1.00 \\
\hline Implied & 1.00 & 1.00 & 1.00 & 1.00 \\
\hline EWMA-IVAR & 1.00 & 1.00 & 1.00 & 1.00 \\
\hline EWMA-ICOV & 1.00 & 1.00 & 1.00 & 1.00 \\
\hline Port. EWMA & $\mathbf{0 . 9 7}$ & 1.00 & $\mathbf{0 . 9 9}$ & 1.00 \\
\hline Port. GARCH & 1.00 & 1.00 & 1.00 & 1.00 \\
\hline
\end{tabular}

Panel D. VaR models based on the nonparametric distributional assumption

\begin{tabular}{|l|l|l|l|l|}
\hline & Test statistics for $\boldsymbol{\alpha}=[\mathbf{0 . 0 1}, \mathbf{0 . 0 5}]$ & \multicolumn{2}{l|}{ Test statistics for $\boldsymbol{\alpha}=[\mathbf{0 . 0 1 , 0 . 1 0 ]}$} \\
\hline $\begin{array}{l}\text { Covariance } \\
\text { specification }\end{array}$ & $\mathbf{L} \mathbf{R}_{\mathrm{uc}}$ & $\mathbf{L} \mathbf{R}_{\mathrm{cc}}$ & $\mathbf{L R}_{\mathrm{uc}}$ & $\mathbf{L R}_{\mathrm{cc}}$ \\
\hline Constant & 0.29 & $\mathbf{1 . 0 0}$ & 0.84 & $\mathbf{1 . 0 0}$ \\
\hline Historical & $\mathbf{0 . 9 7}$ & $\mathbf{1 . 0 0}$ & $\mathbf{0 . 9 8}$ & $\mathbf{1 . 0 0}$ \\
\hline EWMA & 0.63 & $\mathbf{1 . 0 0}$ & 0.65 & $\mathbf{1 . 0 0}$ \\
\hline GARCH-DVEC & 0.02 & $\mathbf{1 . 0 0}$ & 0.59 & $\mathbf{1 . 0 0}$ \\
\hline GARCH-BEKK & 0.04 & $\mathbf{1 . 0 0}$ & 0.63 & $\mathbf{1 . 0 0}$ \\
\hline Implied & 0.70 & $\mathbf{1 . 0 0}$ & $\mathbf{1 . 0 0}$ & $\mathbf{1 . 0 0}$ \\
\hline EWMA-IVAR & 0.34 & $\mathbf{1 . 0 0}$ & 0.94 & $\mathbf{1 . 0 0}$ \\
\hline EWMA-ICOV & $\mathbf{0 . 9 5}$ & $\mathbf{1 . 0 0}$ & $\mathbf{1 . 0 0}$ & $\mathbf{1 . 0 0}$ \\
\hline Port. EWMA & 0.72 & $\mathbf{1 . 0 0}$ & 0.41 & $\mathbf{1 . 0 0}$ \\
\hline Port. GARCH & 0.07 & $\mathbf{1 . 0 0}$ & 0.59 & $\mathbf{1 . 0 0}$ \\
\hline
\end{tabular}




\section{Table 6. Asymptotic p-values for the $L R_{\text {dist }}$ Test Results}

The p-value for the $\mathrm{LR}_{\text {dist }}$ test statistics are reported. The $\mathrm{LR}_{\text {dist }}$ statistic is asymptotically distributed $\chi^{2}(3)$. The shaded cells indicate rejection of the null hypothesis at the $5 \%$ significance level.

\begin{tabular}{|l|l|l|l|l|}
\hline & \multicolumn{4}{|c|}{ Normal transform tests } \\
\hline $\begin{array}{l}\text { Covariance } \\
\text { specification }\end{array}$ & $\begin{array}{l}\text { Standard normal } \\
\text { distribution }\end{array}$ & $\mathbf{t}(\mathbf{1 3})$ distribution & $\begin{array}{l}\text { generalized-t } \\
\text { distribution }\end{array}$ & $\begin{array}{l}\text { nonparametric } \\
\text { distribution }\end{array}$ \\
\hline Constant & $\mathbf{0 . 9 9}$ & $\mathbf{1 . 0 0}$ & $\mathbf{0 . 9 6}$ & 0.83 \\
\hline Historical & 0.28 & $\mathbf{0 . 9 9}$ & 0.06 & 0.73 \\
\hline EWMA & 0.36 & $\mathbf{0 . 9 9}$ & 0.08 & 0.64 \\
\hline GARCH-DVEC & 0.88 & $\mathbf{1 . 0 0}$ & 0.36 & 0.28 \\
\hline GARCH-BEKK & 0.72 & $\mathbf{1 . 0 0}$ & 0.18 & 0.19 \\
\hline Implied & $\mathbf{1 . 0 0}$ & $\mathbf{1 . 0 0}$ & $\mathbf{0 . 9 9}$ & $\mathbf{0 . 9 9}$ \\
\hline EWMA-IVAR & $\mathbf{0 . 9 9}$ & $\mathbf{1 . 0 0}$ & 0.82 & 0.75 \\
\hline EWMA-ICOV & $\mathbf{1 . 0 0}$ & $\mathbf{1 . 0 0}$ & $\mathbf{0 . 9 9}$ & $\mathbf{0 . 9 9}$ \\
\hline Port. EWMA & 0.50 & $\mathbf{0 . 9 9}$ & 0.28 & 0.92 \\
\hline Port. GARCH & 0.78 & $\mathbf{1 . 0 0}$ & 0.21 & 0.20 \\
\hline
\end{tabular}




\section{Table 7. Asymptotic p-values for the $\mathbf{L R}_{\text {mag }}$ Test Results}

The p-value for the $\mathrm{LR}_{\text {mag }}$ test statistic are reported. The $\mathrm{LR}_{\text {mag }}$ test statistics are asymptotically distributed $\chi^{2}(2)$. The shaded cells indicate rejection of the null hypothesis at the 5\% significance level.

Panel A. VaR models based on the standard normal distributional assumption

\begin{tabular}{|c|c|c|c|c|}
\hline & \multicolumn{4}{|c|}{$\mathbf{L} \mathbf{R}_{\text {mag }}$ tests } \\
\hline $\begin{array}{l}\text { Covariance } \\
\text { specification }\end{array}$ & $\begin{array}{l}1 \% \text { VaR } \\
\text { estimates }\end{array}$ & $\begin{array}{l}5 \% \text { VaR } \\
\text { estimates }\end{array}$ & $\begin{array}{l}10 \% \text { VaR } \\
\text { estimates }\end{array}$ & $\begin{array}{l}25 \% \text { VaR } \\
\text { estimates }\end{array}$ \\
\hline Constant & 0.98 & 1.00 & 1.00 & 1.00 \\
\hline Historical & 0.05 & 0.64 & 0.92 & 0.99 \\
\hline EWMA & 0.29 & 0.63 & 0.76 & 0.88 \\
\hline GARCH-DVEC & 0.96 & 0.99 & 1.00 & 1.00 \\
\hline GARCH-BEKK & 0.90 & 0.99 & 0.99 & 0.99 \\
\hline Implied & 0.99 & 1.00 & 1.00 & 1.00 \\
\hline EWMA-IVAR & 0.99 & 1.00 & 1.00 & 1.00 \\
\hline EWMA-ICOV & 0.99 & 1.00 & 1.00 & 1.00 \\
\hline Port. EWMA & 0.09 & 0.85 & 0.99 & 1.00 \\
\hline Port. GARCH & 0.92 & 0.99 & 0.99 & 0.99 \\
\hline
\end{tabular}

Panel B. VaR models based on the $t(13)$ distributional assumption

\begin{tabular}{|l|l|l|l|l|}
\hline & \multicolumn{5}{|c|}{ LR $_{\text {mag }}$ tests } \\
\hline $\begin{array}{l}\text { Covariance } \\
\text { specification }\end{array}$ & $\begin{array}{l}\text { 1\% VaR } \\
\text { estimates }\end{array}$ & $\begin{array}{l}5 \% \text { VaR } \\
\text { estimates }\end{array}$ & $\begin{array}{l}10 \% \text { VaR } \\
\text { estimates }\end{array}$ & $\begin{array}{l}25 \% \text { VaR } \\
\text { estimates }\end{array}$ \\
\hline Constant & 0.99 & 1.00 & 1.00 & 1.00 \\
\hline Historical & 0.99 & 1.00 & 1.00 & 1.00 \\
\hline EWMA & 1.00 & 1.00 & 1.00 & 1.00 \\
\hline GARCH-DVEC & 0.99 & 1.00 & 1.00 & 1.00 \\
\hline GARCH-BEKK & 0.99 & 1.00 & 1.00 & 1.00 \\
\hline Implied & 1.00 & 1.00 & 1.00 & 1.00 \\
\hline EWMA-IVAR & 0.99 & 1.00 & 1.00 & 1.00 \\
\hline EWMA-ICOV & 1.00 & 1.00 & 1.00 & 1.00 \\
\hline Port. EWMA & 0.99 & 1.00 & 1.00 & 1.00 \\
\hline Port. GARCH & 0.99 & 1.00 & 1.00 & 1.00 \\
\hline
\end{tabular}


Panel C. VaR models based on the generalized t-distributional assumption

\begin{tabular}{|c|c|c|c|c|}
\hline \multirow[b]{2}{*}{$\begin{array}{l}\text { Covariance } \\
\text { specification }\end{array}$} & \multicolumn{4}{|c|}{$\mathbf{L R}_{\text {mag }}$ tests } \\
\hline & $\begin{array}{l}1 \% \text { VaR } \\
\text { estimates }\end{array}$ & $\begin{array}{l}5 \% \text { VaR } \\
\text { estimates }\end{array}$ & $\begin{array}{l}10 \% \text { VaR } \\
\text { estimates }\end{array}$ & $\begin{array}{l}25 \% \text { VaR } \\
\text { estimates }\end{array}$ \\
\hline Constant & 0.99 & 1.00 & 1.00 & 1.00 \\
\hline Historical & 0.04 & 0.46 & 0.84 & 0.99 \\
\hline EWMA & 0.02 & 0.34 & 0.72 & 0.98 \\
\hline GARCH-DVEC & 0.87 & 0.99 & 0.99 & 0.99 \\
\hline GARCH-BEKK & 0.76 & 0.99 & 0.99 & 0.98 \\
\hline Implied & 0.99 & 1.00 & 1.00 & 1.00 \\
\hline EWMA-IVAR & 0.98 & 1.00 & 1.00 & 1.00 \\
\hline EWMA-ICOV & 0.99 & 1.00 & 1.00 & 1.00 \\
\hline Port. EWMA & 0.09 & 0.76 & 0.99 & 1.00 \\
\hline Port. GARCH & 0.78 & 0.99 & 0.99 & 0.98 \\
\hline
\end{tabular}

Panel D. VaR models based on the nonparametric distributional assumption

\begin{tabular}{|c|c|c|c|c|}
\hline \multirow[b]{2}{*}{$\begin{array}{l}\text { Covariance } \\
\text { specification }\end{array}$} & \multicolumn{4}{|c|}{$\mathbf{L R}_{\text {mag }}$ tests } \\
\hline & $\begin{array}{l}1 \% \text { VaR } \\
\text { estimates }\end{array}$ & $\begin{array}{l}5 \% \text { VaR } \\
\text { estimates }\end{array}$ & $\begin{array}{l}10 \% \text { VaR } \\
\text { estimates }\end{array}$ & $\begin{array}{l}25 \% \text { VaR } \\
\text { estimates }\end{array}$ \\
\hline Constant & 0.97 & 1.00 & 1.00 & 1.00 \\
\hline Historical & 0.03 & 0.97 & 0.99 & 1.00 \\
\hline EWMA & 0.01 & 0.94 & 0.99 & 1.00 \\
\hline GARCH-DVEC & 0.78 & 0.99 & 0.99 & 1.00 \\
\hline GARCH-BEKK & 0.52 & 0.94 & 0.99 & 0.99 \\
\hline Implied & 0.99 & 1.00 & 1.00 & 1.00 \\
\hline EWMA-IVAR & 0.96 & 1.00 & 1.00 & 1.00 \\
\hline EWMA-ICOV & 0.99 & 1.00 & 1.00 & 1.00 \\
\hline Port. EWMA & 0.16 & 0.99 & 1.00 & 1.00 \\
\hline Port. GARCH & 0.55 & 0.95 & 1.00 & 1.00 \\
\hline
\end{tabular}


Table 8. Exception frequency as a percentage of out-of-sample, 250-trading day periods

Each cell presents the percentage of the 1430 overlapping 250-day periods in the out-of-sample period for which these number of VaR exceptions are observed.

Panel A. Standard normal distribution

\begin{tabular}{|l|l|l|l|l|l|}
\hline & \multicolumn{5}{|c|}{ Number of VaR exceptions } \\
\hline $\begin{array}{l}\text { Covariance } \\
\text { specification }\end{array}$ & $\mathbf{0}$ & $\mathbf{5}$ & $\mathbf{4}$ & $\mathbf{5}$ & $\mathbf{9}$ \\
\hline Constant & 25 & 67 & 74 & 100 & 100 \\
\hline Historical & 1 & 55 & 70 & 100 & 100 \\
\hline EWMA & 0 & 66 & 80 & 100 & 100 \\
\hline GARCH-DVC & 0 & 84 & 93 & 100 & 100 \\
\hline GARCH-BEKK & 0 & 79 & 93 & 100 & 100 \\
\hline Implied & 9 & 92 & 100 & 100 & 100 \\
\hline EWMA-IVAR & 1 & 70 & 84 & 100 & 100 \\
\hline EWMA-ICOV & 0 & 74 & 87 & 100 & 100 \\
\hline Port. EWMA & 0 & 77 & 87 & 100 & 100 \\
\hline Port. GARCH & 0 & 75 & 95 & 100 & 100 \\
\hline
\end{tabular}

Panel B. t(13) distribution

\begin{tabular}{|l|l|l|l|l|l|}
\hline & \multicolumn{5}{|c|}{ Number of VaR exceptions } \\
\hline $\begin{array}{l}\text { Covariance } \\
\text { specification }\end{array}$ & $\mathbf{0}$ & $\mathbf{5}$ & $\mathbf{4}$ & $\mathbf{5}$ & $\leq \mathbf{1 0}$ \\
\hline Constant & 26 & 79 & 87 & 100 & 100 \\
\hline Historical & 0 & 20 & 95 & 100 & 100 \\
\hline EWMA & 0 & 100 & 100 & 100 & 100 \\
\hline $\begin{array}{l}\text { GARCH- } \\
\text { DVEC }\end{array}$ & 0 & 100 & 100 & 100 & 100 \\
\hline GARCH-BEKK & 5 & 96 & 100 & 100 & 100 \\
\hline Implied & 26 & 100 & 100 & 100 & 100 \\
\hline EWMA-IVAR & 22 & 100 & 100 & 100 & 100 \\
\hline EWMA-ICOV & 8 & 89 & 94 & 100 & 100 \\
\hline Port. EWMA & 15 & 26 & 35 & 100 & 100 \\
\hline Port. GARCH & 0 & 100 & 100 & 100 & 100 \\
\hline
\end{tabular}


Panel C. Generalized-t distribution

\begin{tabular}{|l|l|l|l|l|l|}
\hline & \multicolumn{5}{|c|}{ Number of exceptions } \\
\hline $\begin{array}{l}\text { Covariance } \\
\text { specification }\end{array}$ & $\mathbf{0}$ & $\mathbf{5}$ & $\leq \mathbf{5}$ & $\leq \mathbf{9}$ & $\leq \mathbf{1 0}$ \\
\hline Constant & 50 & 100 & 100 & 100 & 100 \\
\hline Historical & 24 & 100 & 100 & 100 & 100 \\
\hline EWMA & 30 & 100 & 100 & 100 & 100 \\
\hline $\begin{array}{l}\text { GARCH- } \\
\text { DVEC }\end{array}$ & 47 & 100 & 100 & 100 & 100 \\
\hline GARCH-BEKK & 43 & 100 & 100 & 100 & 100 \\
\hline Implied & 61 & 100 & 100 & 100 & 100 \\
\hline EWMA-IVAR & 38 & 100 & 100 & 100 & 100 \\
\hline EWMA-ICOV & 76 & 100 & 100 & 100 & 100 \\
\hline Port. EWMA & 43 & 100 & 100 & 100 & 100 \\
\hline Port. GARCH & 22 & 100 & 100 & 100 & 100 \\
\hline
\end{tabular}

Panel D. Nonparametric distribution

\begin{tabular}{|c|c|c|c|c|c|}
\hline \multirow[b]{2}{*}{$\begin{array}{l}\text { Covariance } \\
\text { specification }\end{array}$} & \multicolumn{5}{|c|}{ Number of exceptions } \\
\hline & $\mathbf{0}$ & $\leq 4$ & $\leq 5$ & $\leq 9$ & $\leq \mathbf{1 0}$ \\
\hline Constant & 26 & 67 & 77 & 100 & 100 \\
\hline Historical & 1 & 60 & 71 & 100 & 100 \\
\hline EWMA & 0 & 91 & 100 & 100 & 100 \\
\hline $\begin{array}{l}\text { GARCH- } \\
\text { DVEC }\end{array}$ & 0 & 93 & 100 & 100 & 100 \\
\hline GARCH-BEKK & 0 & 83 & 93 & 100 & 100 \\
\hline Implied & 0 & 9 & 97 & 100 & 100 \\
\hline EWMA-IVAR & 9 & 97 & 100 & 100 & 100 \\
\hline EWMA-ICOV & 1 & 100 & 100 & 100 & 100 \\
\hline Port. EWMA & 0 & 85 & 87 & 100 & 100 \\
\hline Port. GARCH & 0 & 95 & 97 & 100 & 100 \\
\hline
\end{tabular}


Table 9. Percentage of trading days for which the defined capital charge for EWMANormal model is below the other model's capital charge

\begin{tabular}{|l|l|l|l|l|}
\hline $\begin{array}{l}\text { Covariance } \\
\text { specification }\end{array}$ & $\begin{array}{l}\text { Standard normal } \\
\text { distribution }\end{array}$ & $\mathbf{t}(\mathbf{1 3})$ distribution & $\begin{array}{l}\text { generalized-t } \\
\text { distribution }\end{array}$ & $\begin{array}{l}\text { nonparametric } \\
\text { distribution }\end{array}$ \\
\hline Constant & 73.9 & 83.8 & 93.5 & 79.8 \\
\hline Historical & 64.9 & 78.5 & 99.9 & 76.0 \\
\hline EWMA & $\mathbf{X X X X X}$ & 80.0 & 100.0 & 71.0 \\
\hline GARCH-DVEC & 57.0 & 83.1 & 100.0 & 65.9 \\
\hline GARCH-BEKK & 56.8 & 82.4 & 100.0 & 70.5 \\
\hline Implied & 68.3 & 88.5 & 100.0 & 79.5 \\
\hline EWMA-IVAR & 74.9 & 85.9 & 100.0 & 70.4 \\
\hline EWMA-ICOV & 65.3 & 80.5 & 100.0 & 79.6 \\
\hline Port. EWMA & 30.8 & 74.1 & 100.0 & 48.8 \\
\hline Port. GARCH & 58.2 & 77.6 & 100.0 & 72.2 \\
\hline
\end{tabular}


Table 10. p-value of the Diebold \& Mariano statistic for capital charges corresponding to the models' 1\% VaR estimates relative to those of the EWMA-normal model

The shaded cells indicate that the null hypothesis of equal capital charges is rejected at the 5\% significance level.

\begin{tabular}{|l|l|l|l|l|}
\hline $\begin{array}{l}\text { Covariance } \\
\text { specification }\end{array}$ & $\begin{array}{l}\text { Standard normal } \\
\text { distribution }\end{array}$ & $\mathbf{t}(\mathbf{1 3})$ distribution & $\begin{array}{l}\text { generalized-t } \\
\text { distribution }\end{array}$ & $\begin{array}{l}\text { nonparametric } \\
\text { distribution }\end{array}$ \\
\hline Constant & $1.1 \%$ & $0.0 \%$ & $0.0 \%$ & $0.0 \%$ \\
\hline Historical & $3.0 \%$ & $0.0 \%$ & $0.0 \%$ & $0.1 \%$ \\
\hline EWMA & $\mathbf{S X X X 8}$ & $0.0 \%$ & $0.0 \%$ & $24.8 \%$ \\
\hline GARCH-DVEC & $57.0 \%$ & $0.0 \%$ & $0.0 \%$ & $7.4 \%$ \\
\hline GARCH-BEKK & $55.6 \%$ & $0.0 \%$ & $0.0 \%$ & $1.9 \%$ \\
\hline Implied & $2.1 \%$ & $0.0 \%$ & $0.0 \%$ & $0.0 \%$ \\
\hline EWMA-IVAR & $0.4 \%$ & $0.0 \%$ & $0.0 \%$ & $0.8 \%$ \\
\hline EWMA-ICOV & $34.4 \%$ & $0.0 \%$ & $0.0 \%$ & $0.0 \%$ \\
\hline Port. EWMA & $\mathbf{9 8 . 2 \%}$ & $0.3 \%$ & $0.0 \%$ & $80.3 \%$ \\
\hline Port. GARCH & $33.0 \%$ & $0.0 \%$ & $0.0 \%$ & $1.0 \%$ \\
\hline
\end{tabular}

Table 11. p-value of the Diebold \& Mariano statistic for capital charges corresponding to the models' $1 \%$ VaR estimates relative to those of the port.EWMA-normal model

The shaded cells indicate that the null hypothesis of equal capital charges is rejected at the $5 \%$ significance level.

\begin{tabular}{|l|l|l|l|l|}
\hline $\begin{array}{l}\text { Covariance } \\
\text { specification }\end{array}$ & $\begin{array}{l}\text { Standard normal } \\
\text { distribution }\end{array}$ & $\mathbf{t}(\mathbf{1 3})$ distribution & $\begin{array}{l}\text { generalized-t } \\
\text { distribution }\end{array}$ & $\begin{array}{l}\text { nonparametric } \\
\text { distribution }\end{array}$ \\
\hline Constant & $0.0 \%$ & $0.0 \%$ & $0.0 \%$ & $0.0 \%$ \\
\hline Historical & $1.6 \%$ & $0.0 \%$ & $0.0 \%$ & $0.2 \%$ \\
\hline EWMA & $1.8 \%$ & $0.0 \%$ & $0.0 \%$ & $0.1 \%$ \\
\hline GARCH-DVEC & $1.5 \%$ & $0.0 \%$ & $0.0 \%$ & $0.0 \%$ \\
\hline GARCH-BEKK & $2.6 \%$ & $0.0 \%$ & $0.0 \%$ & $0.0 \%$ \\
\hline Implied & $0.0 \%$ & $0.0 \%$ & $0.0 \%$ & $0.0 \%$ \\
\hline EWMA-IVAR & $0.1 \%$ & $0.0 \%$ & $0.0 \%$ & $0.0 \%$ \\
\hline EWMA-ICOV & $4.0 \%$ & $0.0 \%$ & $0.0 \%$ & $0.0 \%$ \\
\hline Port. EWMA & $\mathbf{X X X X X X X}$ & $0.0 \%$ & $0.0 \%$ & $0.3 \%$ \\
\hline Port. GARCH & $0.4 \%$ & $0.0 \%$ & $0.0 \%$ & $0.0 \%$ \\
\hline
\end{tabular}

